\title{
lodine Sorbent Performance in FY 2012 Deep Bed Tests
}

\author{
Nick Soelberg \\ Tony Watson
}

August 2012

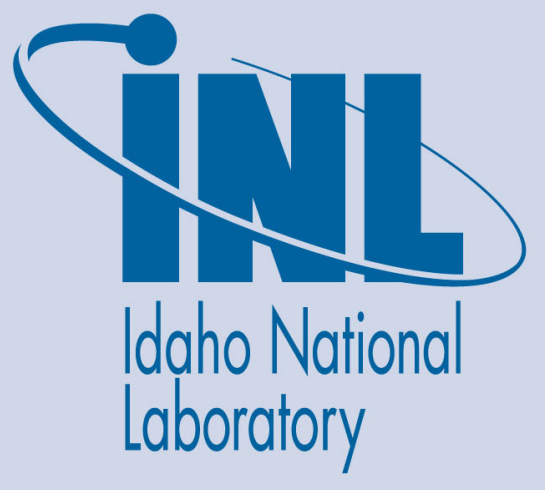

The INL is a U.S. Department of Energy National Laboratory operated by Battelle Energy Alliance 
INL/EXT-12-27075

FCRD-SWF-2012-000278

\title{
lodine Sorbent Performance in FY 2012 Deep Bed Tests
}

\author{
Nick Soelberg
}

Tony Watson

August 2012

\section{Idaho National Laboratory \\ Fuel Cycle Research \& Development \\ Idaho Falls, Idaho 83415}

http://www.inl.gov

Prepared for the

U.S. Department of Energy

Office of Nuclear Energy

Under DOE Idaho Operations Office

Contract DE-AC07-05ID14517 


\section{DISCLAIMER}

This information was prepared as an account of work sponsored by an agency of the U.S. Government. Neither the U.S. Government nor any agency thereof, nor any of their employees, makes any warranty, expressed or implied, or assumes any legal liability or responsibility for the accuracy, completeness, or usefulness, of any information, apparatus, product, or process disclosed, or represents that its use would not infringe privately owned rights. References herein to any specific commercial product, process, or service by trade name, trade mark, manufacturer, or otherwise, does not necessarily constitute or imply its endorsement, recommendation, or favoring by the U.S. Government or any agency thereof. The views and opinions of authors expressed herein do not necessarily state or reflect those of the U.S. Government or any agency thereof. 


\section{ACKNOWLEDGEMENTS}

We acknowledge others who helped guide or perform iodine sorption testing this year. Jack Law of the Idaho National Laboratory (INL) Aqueous Separations and Radiochemistry Department and the Department of Energy Fuel Cycle Research and Development Program Separations and Waste Forms Campaign, and Bob Jubin of the Oak Ridge National Laboratory (ORNL), and the leader of the Separations and Waste Forms Campaign Off-gas Sigma Team, provided programmatic and technical direction. Joseph Matyas of Pacific Northwest National Laboratory provided the silver-functionalized Aerogel that was tested.

Veronica Rutledge of the INL Aqueous Separations and Radiochemistry Department helped in test planning. Duane Ball and others in the INL Chemistry and Radiation Measurement Department performed iodine sample analyses. Daren Jensen provided quality assurance guidance. 
lodine Sorbent Performance in FY 2012 Deep Bed Tests

This page intentionally left blank 


\section{SUMMARY}

Nuclear fission results in the production of fission products and activation products, some of which tend to be volatile during used fuel reprocessing and evolve in gaseous species into the reprocessing facility off-gas systems. Analyses have shown that I-129, due to its radioactivity, high potential mobility in the environment, and high longevity (half life of 15.7 million years), can require control efficiencies of up to $1,000 \mathrm{x}$ or higher to meet regulatory emission limits. Iodine capture is an important aspect of the Separations and Waste Forms Campaign Off-gas Sigma Team (Jubin 2011, Pantano 2011).

Deep-bed iodine sorption tests for both silver-functionalized Aerogel and silver zeolite sorbents were performed during Fiscal Year 2012. These tests showed that:

- Decontamination factors (DFs) were achieved that exceed reasonably conservative estimates for DFs needed for used fuel reprocessing facilities in the U.S. to meet regulatory requirements for I129 capture.

- Silver utilizations approached or exceeded $100 \%$ for high inlet gas iodine concentrations, but test durations were not long enough to approach $100 \%$ silver utilization for lower iodine concentrations.

- The depth of the mass transfer zone (MTZ) was determined for both low iodine concentrations (under $10 \mathrm{ppmv}$ ) and for higher iodine concentrations (between 10-50 ppmv). Higher inlet iodine concentrations cause deeper MTZs because of the increased mass transfer that has to occur; also, the MTZ depth increases over time as the iodine is adsorbed.

- These sorbents capture iodine by chemisorption, where the adsorbed iodine reacts with the silver to form very non-volatile AgI. Any adsorbed iodine that is physisorbed but not chemically reacted with silver to form AgI might not be tightly held by the sorbent. The portion of adsorbed iodine that tends to desorb because it is not chemisorbed (reacted to form AgI) is small, under $1 \%$, for the AgZ tests, and even smaller, under $0.01 \%$, for the silver-functionalized Aerogel. 
This page intentionally left blank 


\section{TABLE OF CONTENTS}

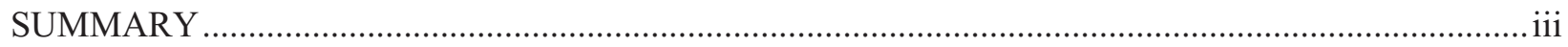

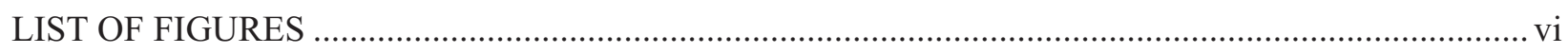

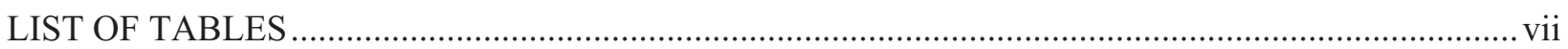

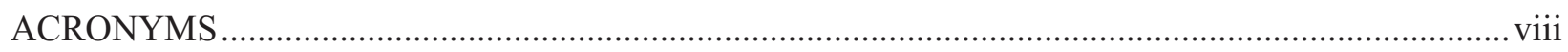

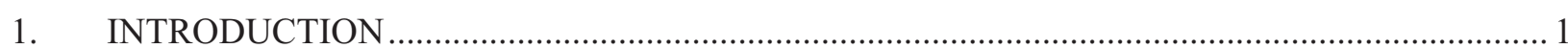

2. DEEP BED IODINE SORBENT TEST SYSTEM ................................................................. 3

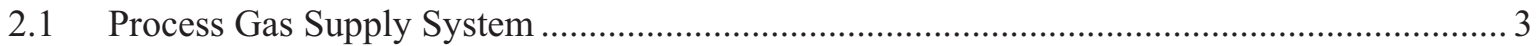

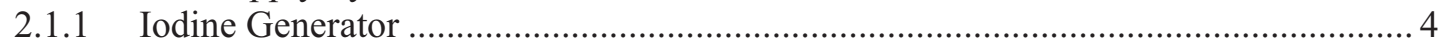

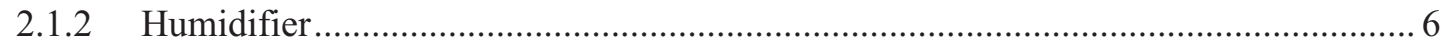

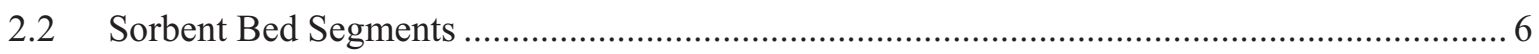

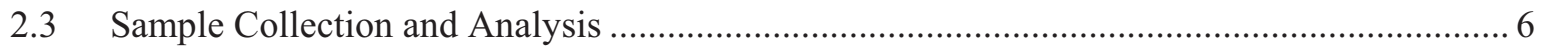

2.3.1 Iodine Sample Collection and Analysis .................................................................. 7

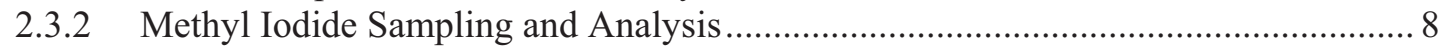

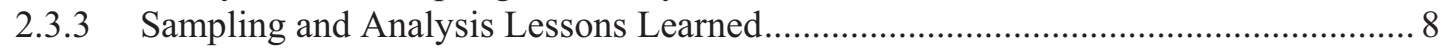

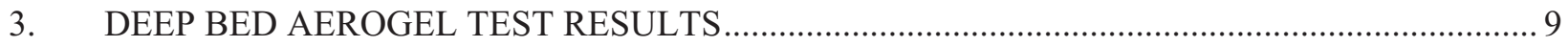

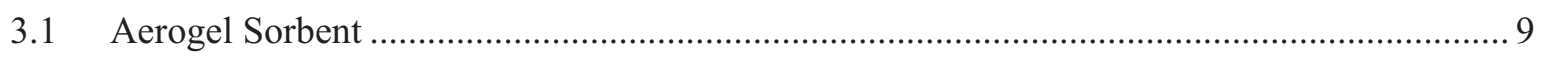

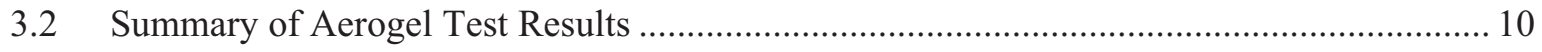

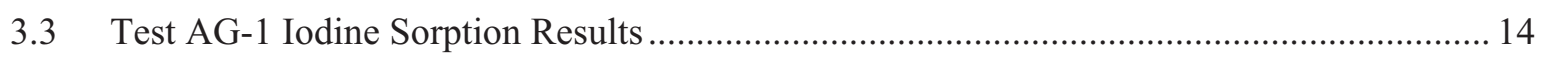

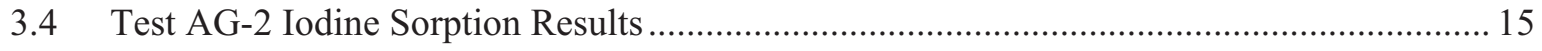

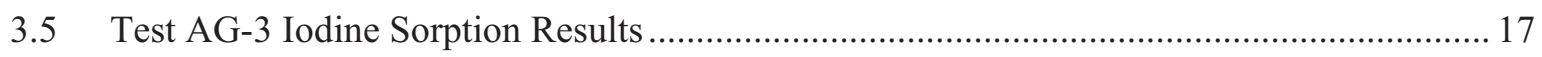

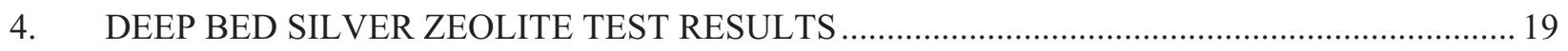

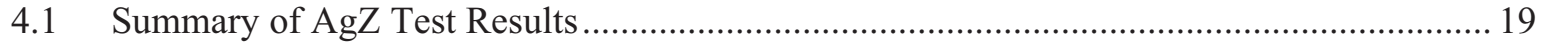

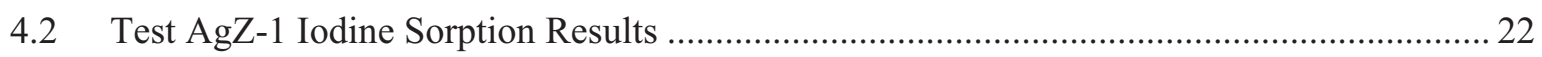

4.3 Test AgZ-2 Iodine Sorption Results ...................................................................... 24

4.4 Test AgZ-3 and AgZ-6 Iodine Sorption Results .............................................................. 26

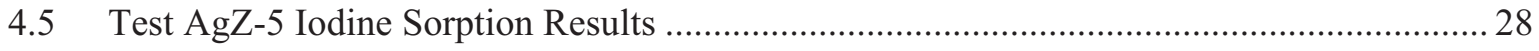

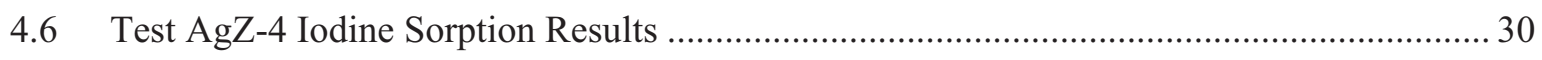

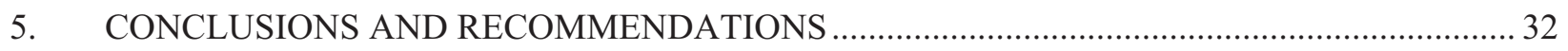

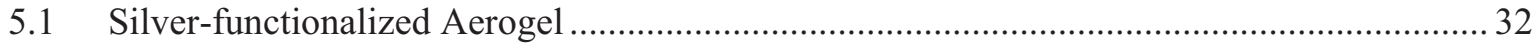

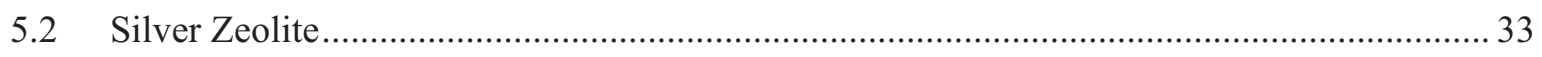

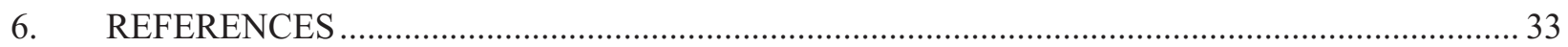




\section{LIST OF FIGURES}

Figure 1-1. Iodine control and waste form research and development interfaces within the Off-

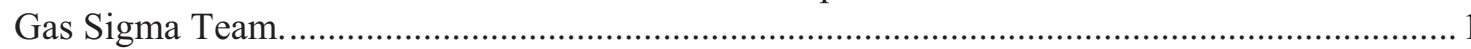

Figure 1-2. Illustration of potential off-gas streams from an aqueous separations plant. ......................... 3

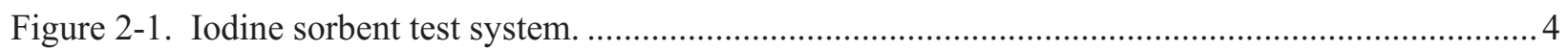

Figure 2-2. View of the iodine bubblers, the permeation tube iodine or methyl iodide generator,

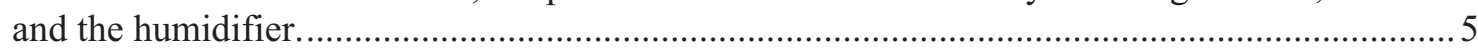

Figure 2-3. First, second, and third generation iodine generators for high iodine flowrates. .................... 5

Figure 2-4. Opened iodine generator showing the glass beads and iodine crystals dispersed

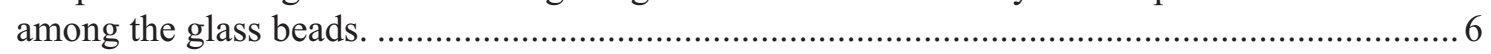

Figure 2-5. Detail of the sorbent beds. At times, only 3 instead of all 4 beds are used.......................... 7

Figure 2-6. Configuration of the sorbent beds inside the temperature-controlled oven............................ 8

Figure 3-1. As-received silver-functionalized Aerogel from PNNL .....................................................

Figure 3-2. Silver-functionalized Aerogel during and after iodine sorption testing. With gas flowing up through the beds, the color gradually changed to a rusty-red-black mix (top left) and then to a grey-yellow-black mix (top right and bottom photos) .................................. 10

Figure 3-3. Classic mass transfer zone progression through the depth of a fixed bed over time............... 12

Figure 3-4. Apparent mass transfer zone observed during the deep-bed tests....................................... 12

Figure 3-5. Maximum sorbent loadings based on the inlet and outlet gas iodine concentrations for

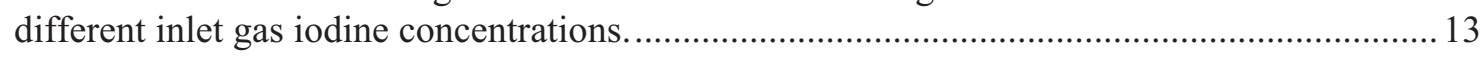

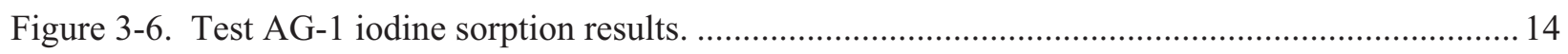

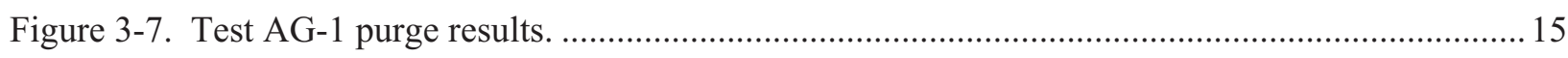

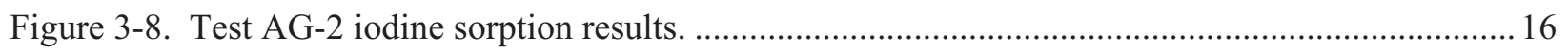

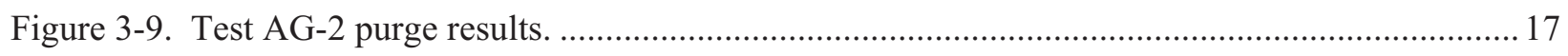

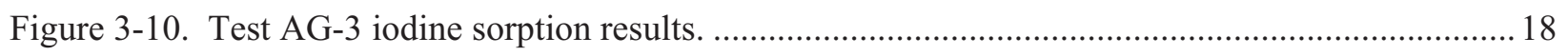

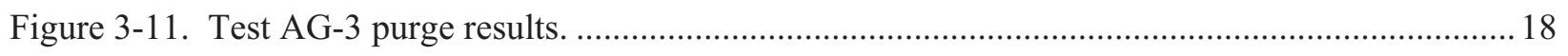

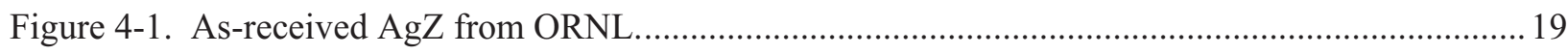

Figure 4-2. AgZ after iodine sorption testing. The dark grey-black color has turned to a yellowbeige color. 20

Figure 4-3. Maximum AgZ sorbent loadings based on the inlet and outlet gas iodine concentrations for different inlet gas iodine concentrations...............................................22

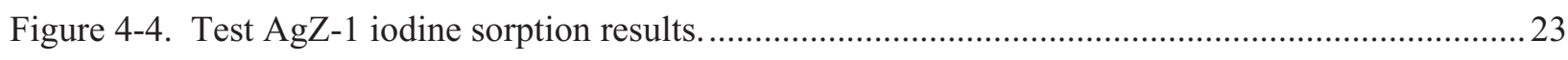

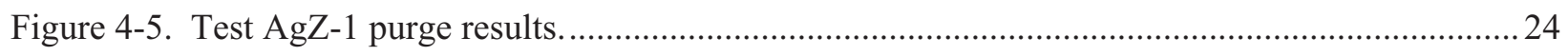

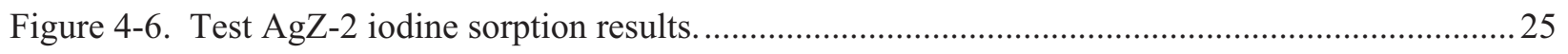

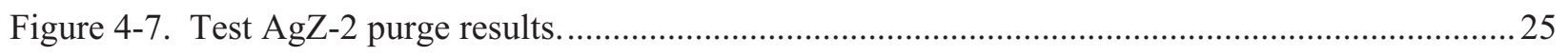

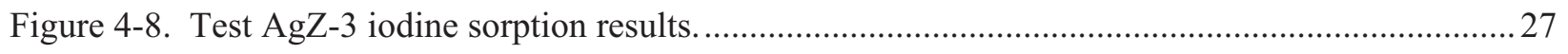

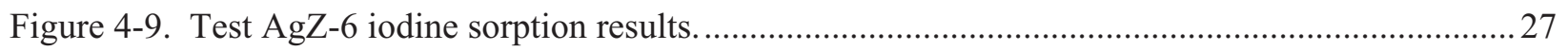




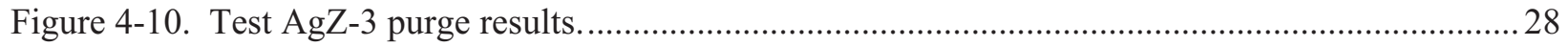

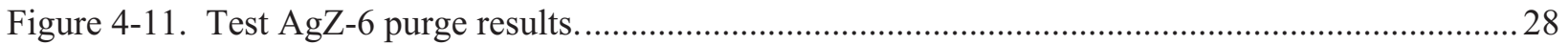

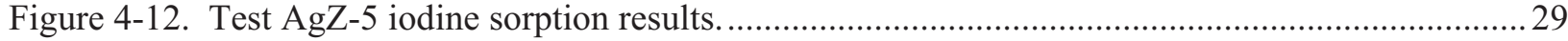

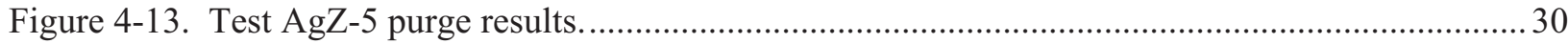

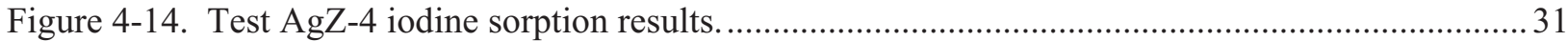

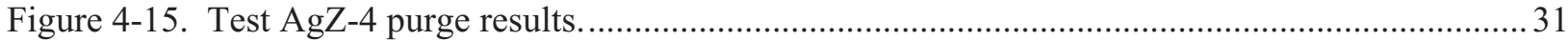

\section{LIST OF TABLES}

Table 3-1. Silver-functionalized Aerogel sorption test conditions. ..................................................... 11

Table 3-2. Silver-functionalized Aerogel sorption test results........................................................... 13

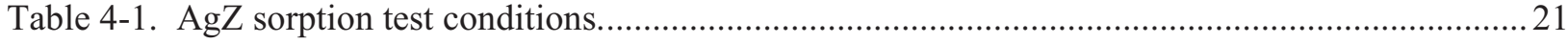

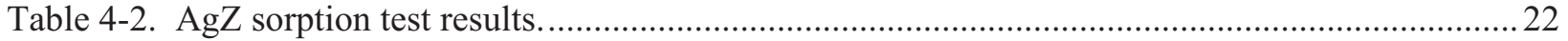




\section{ACRONYMS}

$\begin{array}{ll}\text { BET } & \text { Brunauer, Emmett, and Teller } \\ \text { DF } & \text { decontamination factors } \\ \text { DOE } & \text { Department of Energy } \\ \text { FCRD } & \text { Fuel Cycle Research and Development } \\ \text { FY } & \text { fiscal year } \\ \text { GC } & \text { gas chromatograph } \\ \text { INL } & \text { Idaho National Laboratory } \\ \text { ICP-MS } & \text { inductively coupled plasma mass spectrometry } \\ \text { MS } & \text { mass spectrometry } \\ \text { MTZ } & \text { mass transfer zone } \\ \text { PNNL } & \text { Pacific Northwest National Laboratory } \\ \text { ORNL } & \text { Oak Ridge National Laboratory }\end{array}$




\section{INTRODUCTION}

Nuclear fission results in the production of fission products and activation products that increasingly interfere with the fission process as their concentrations increase. If used nuclear fuel is reprocessed to separate fission and activation products from re-useable actinides, volatile radionuclides including I-129 would evolve into the process off-gas systems and may require capture to limit emissions to levels within acceptable limits.

Analyses show that I-129, due to its radioactivity, potentially high mobility in the environment, and long half life(15.7 million years), can require control efficiencies of up to $1,000 \mathrm{x}$ or higher to meet regulatory emission limits (Soelberg 2008, Jubin 2012).

The Department of Energy (DOE) Fuel Cycle Research and Development (FCRD) Program has supported research and development on iodine control and iodine waste forms for the past several years. The Offgas Sigma Team was formed in 2009 within the Separations and Waste Forms Campaign to establish a team of researchers from various DOE sites to focus on research and development of emissions control and waste forms for volatile radionuclides. Figure 1-1 shows iodine control and waste form research areas and interfaces within the Off-gas Sigma Team. Deep-bed iodine sorption testing has a unique and important role in the Off-gas Sigma Team iodine research program, recognized in the Fiscal Year (FY) 2011 Off-gas Sigma Team Peer Review (Pantano 2011). The deep bed testing can:

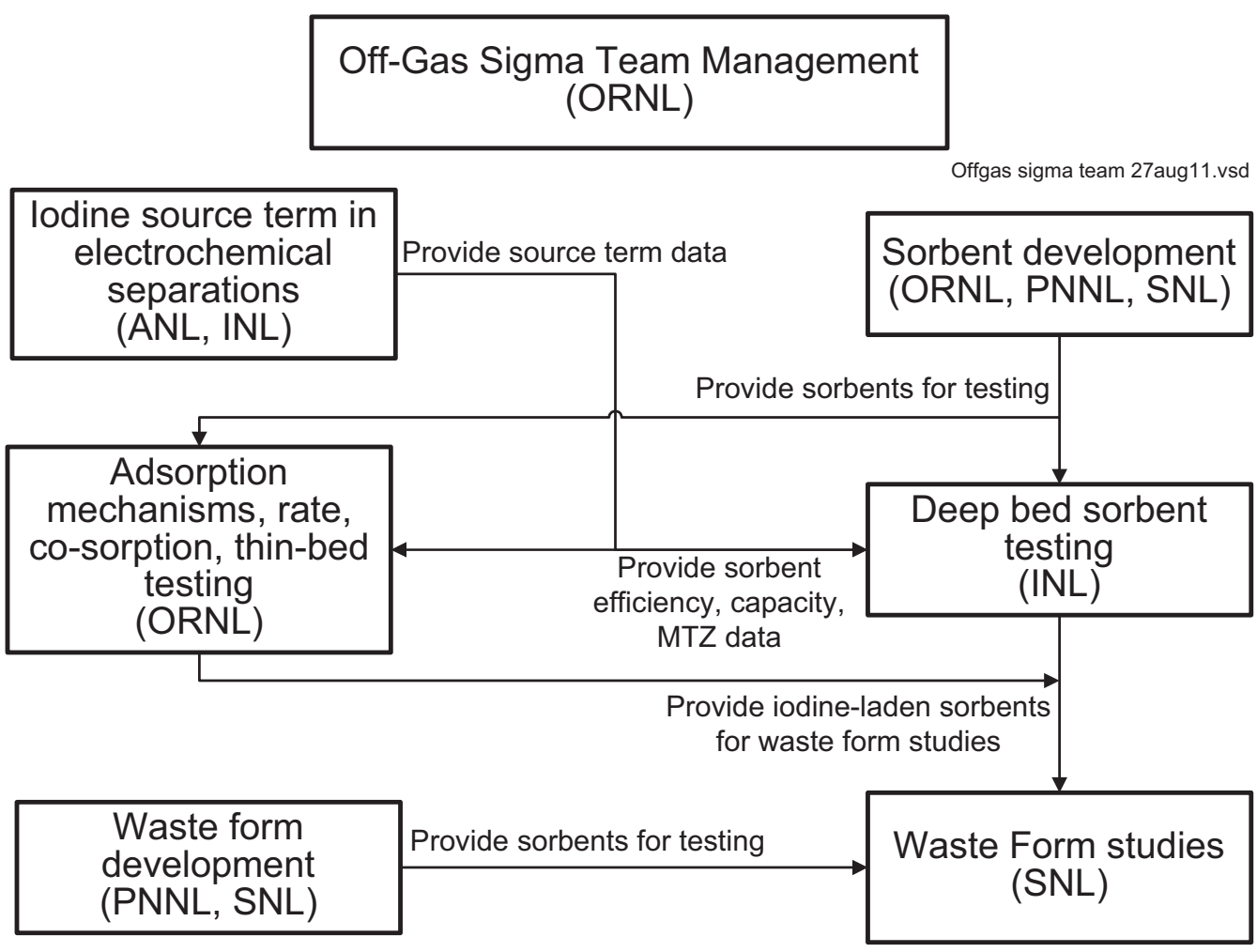

Figure 1-1. Iodine control and waste form research and development interfaces within the Off-Gas Sigma Team.

- Measure sorbent performance under more life-like (but admittedly still idealized) sorption configurations and operating conditions

- Measure sorption efficiencies 
- Measure capacity of sorbents up to breakthrough

- Estimate mass transfer zone (MTZ) depths

- Generate data for isotherms and dynamic modeling

- Produce > gram-quantities of iodine-laden sorbent for confirming Ag and iodine loadings and waste form studies

The objectives of the FY 2012 deep bed iodine sorbent testing were:

- Perform deep bed adsorption testing using silver functionalized aerogel

- Provide sorption data for iodine and methyl iodine dynamic sorption modeling on AgZ

- Support Systems studies performed by the Off-gas Sigma Team.

A test plan was prepared in early FY 2012 (Soelberg 2011), and has been the guiding document for work performed this year. Tests were generally performed for a long-enough duration so that breakthrough occurred, and sorption continued until the sorbent approached saturation conditions. The durations of deep-bed tests this year were generally longer than in prior years, because the test system was upgraded to enable continued unattended operation overnight. All work was performed in compliance to work control documentation that was updated for this year's work, to ensure data quality, worker safety, environmental protection, and regulatory compliance during testing (INL 2011).

The tests were designed to primarily demonstrate the sorbent performance for capturing iodine species in hypothetical aqueous dissolver off-gas, recognizing that a variety of other gas streams could exist in an aqueous separations process; some of which would have considerably different compositions and flowrates. An illustration of these offgas streams is shown in Figure 1-2. The tests enabled the determination of adsorption efficiencies up to the time of and after breakthrough, and sorbent capacities at the time of breakthrough (which is the practical limit to the sorbent capacity and within test duration limits, the potential adsorption capacity of the sorbent under the test conditions).

Tests proceeded to the extent of available funding and time. Not included in the scope of this year's testing were:

- Tests designed to measure iodine sorption and sorbent performance for most separations process gas streams besides the dissolver off-gas

- Tests for evaluating iodine capture and sorbent performance for gas streams from electrochemical processing. 


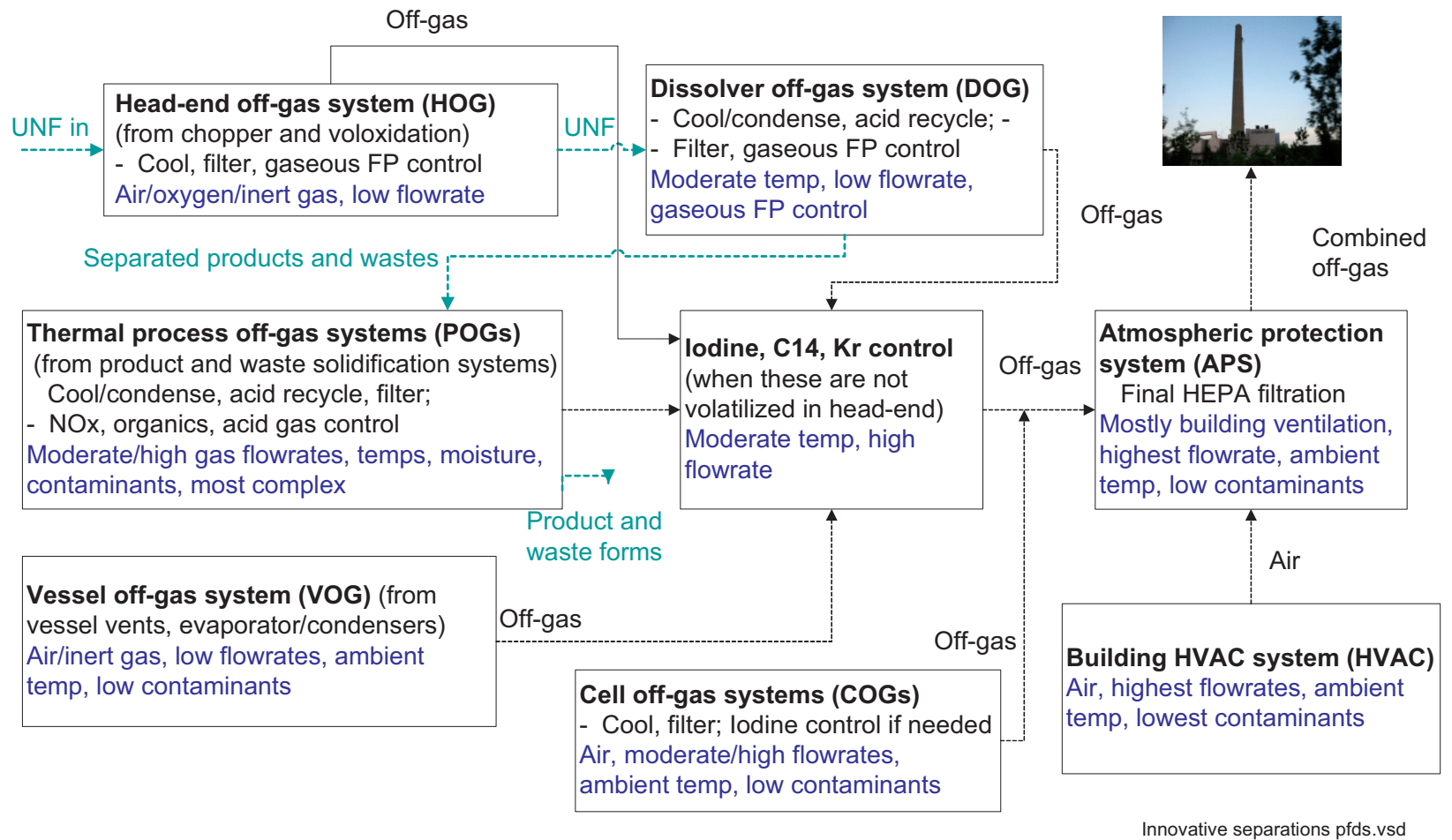

Figure 1-2. Illustration of potential off-gas streams from an aqueous separations plant.

\section{DEEP BED IODINE SORBENT TEST SYSTEM}

Figure 2-1 shows a process diagram for the iodine test system. The main components are:

- Process gas supply and blending system, which supplies gases from gas cylinders, iodine gas species generators, and a humidifier

- Multiple sorbent bed system inside a heated oven

- Process gas bypass

- Inlet and bed segment outlet gas sampling system.

\subsection{Process Gas Supply System}

The process gas supply system consists of pressurized gas cylinders that supply pure air, nitrogen, $\mathrm{NO}_{\mathrm{x}}$, and other gases, iodine and methyl iodide generators, and a humidifier that supplies vaporized water. Air or $\mathrm{N}_{2}$ can be supplied through mass flow controllers separately to the iodine and methyl iodide generators and the humidifier. $\mathrm{NO}$ and $\mathrm{NO}_{2}$ gases, with balance $\mathrm{N}_{2}$, are supplied from compressed gas cylinders through mass flow controllers. The gas flowrates and the generation rates of vaporized iodine, methyl iodide, and water are set to achieve the target gas composition and blended in a mixing chamber upstream of the sorbent beds. All process lines that contain vaporized iodine, methyl iodide, or water are electrically heat traced. 


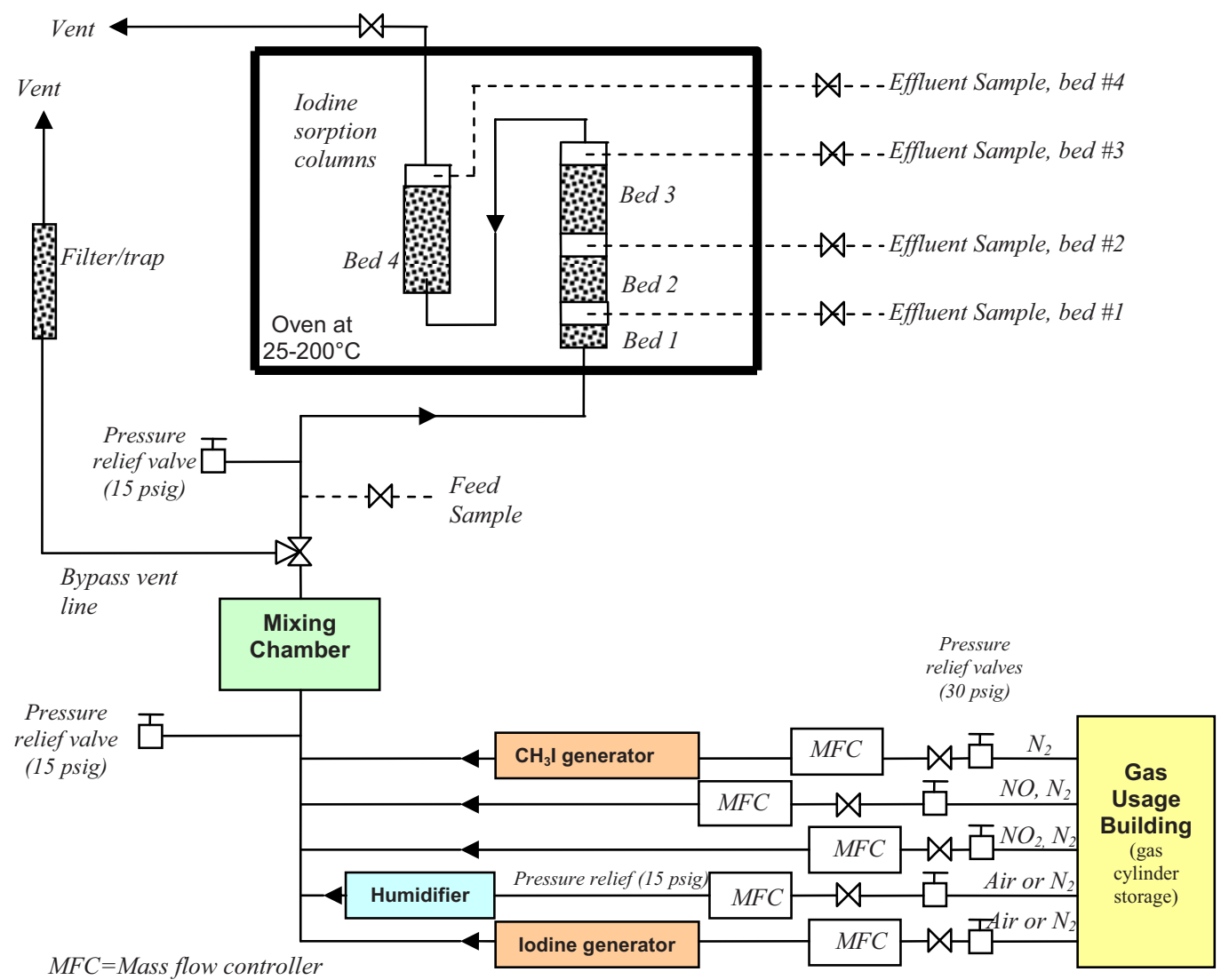

Figure 2-1. Iodine sorbent test system.

\subsection{1 lodine Generator}

Three versions of iodine generators have been tested and used in this year or prior years. When low concentrations of iodine, below about 1 ppmv in the blended gas, are desired, then iodine can be generated using a permeation tube system. Permeation tubes contain solid iodine crystals in semipermeable tubes. The tubes emit a known flowrate of iodine at a constant rate which is controlled by the operating temperature of the tube. The tubes (up to two), from VICI Metronics, are placed inside a Dynacalibrator Model 190 constant temperature permeation tube system (shown in Figure 2-2) also from VICI Metronics.

The VICI Metronics permeation tube system cannot operate at temperatures above $110^{\circ} \mathrm{C}$, the upper limit that the materials of construction can tolerate. The maximum iodine flowrate that can be supplied from a maximum of two permeation tubes at this temperature enables an iodine concentration of about 1 ppmv in the blended gas mixtures at a total gas flowrate of about $1.5-2 \mathrm{~L} / \mathrm{min}$. This gas flowrate provides the desired superficial gas velocities in the sorbent beds of up to $10 \mathrm{~m} / \mathrm{min}$, in the target range of sorbent operating temperatures of about $25-150^{\circ} \mathrm{C}$. For higher iodine flowrates needed for higher iodine concentrations, three types of fixed bed iodine generators were tested, and the third was found to be most acceptable. 


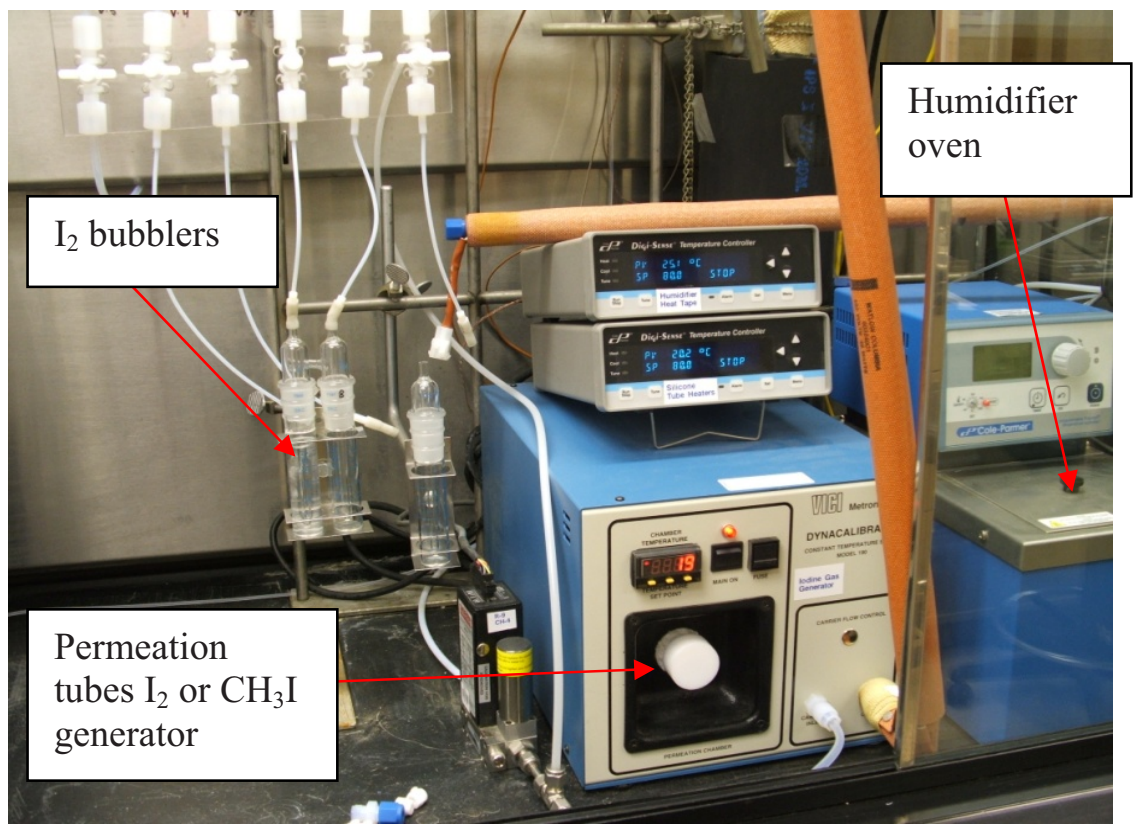

Figure 2-2. View of the iodine bubblers, the permeation tube iodine or methyl iodide generator, and the humidifier.

Figure 2-3 shows the third generation iodine generator, which was tested and found to be superior to the other two versions. In this version, iodine crystals were mixed with glass beads and placed inside the Teflon vessel. The iodine crystals are distributed among the glass beads, which reduces the tendency of the crystals to clump together (shown in Figure 2-4). This design, although it still did not provide the maximum flowrate expected if the sublimation process was in thermodynamic solid-gas equilibrium, provided the most constant flowrate. The iodine flowrate and concentration in the blended gas stream was measured periodically whenever the bed outlet iodine concentrations were measured.

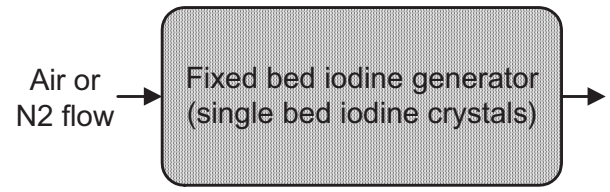

A. Single bed of iodine crystals that tended to clump together and reduce iodine ablation rate.

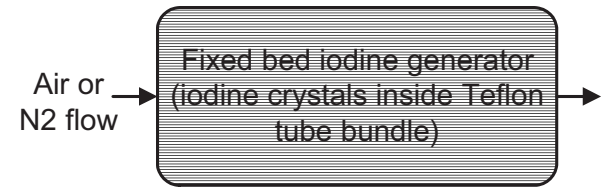

B. lodine crystals inside a bundle of Teflon tubing; clumping was reduced.

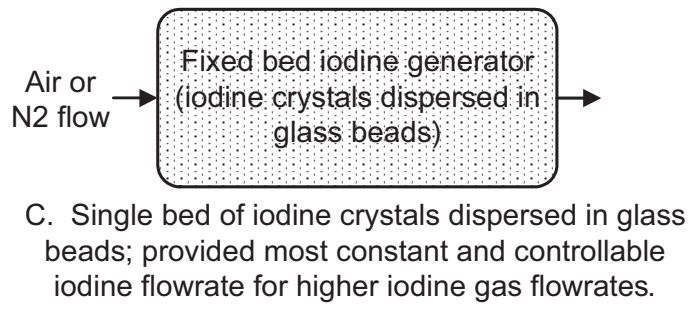

Offgas sigma team 27aug11.vsd

Figure 2-3. First, second, and third generation iodine generators for high iodine flowrates. 


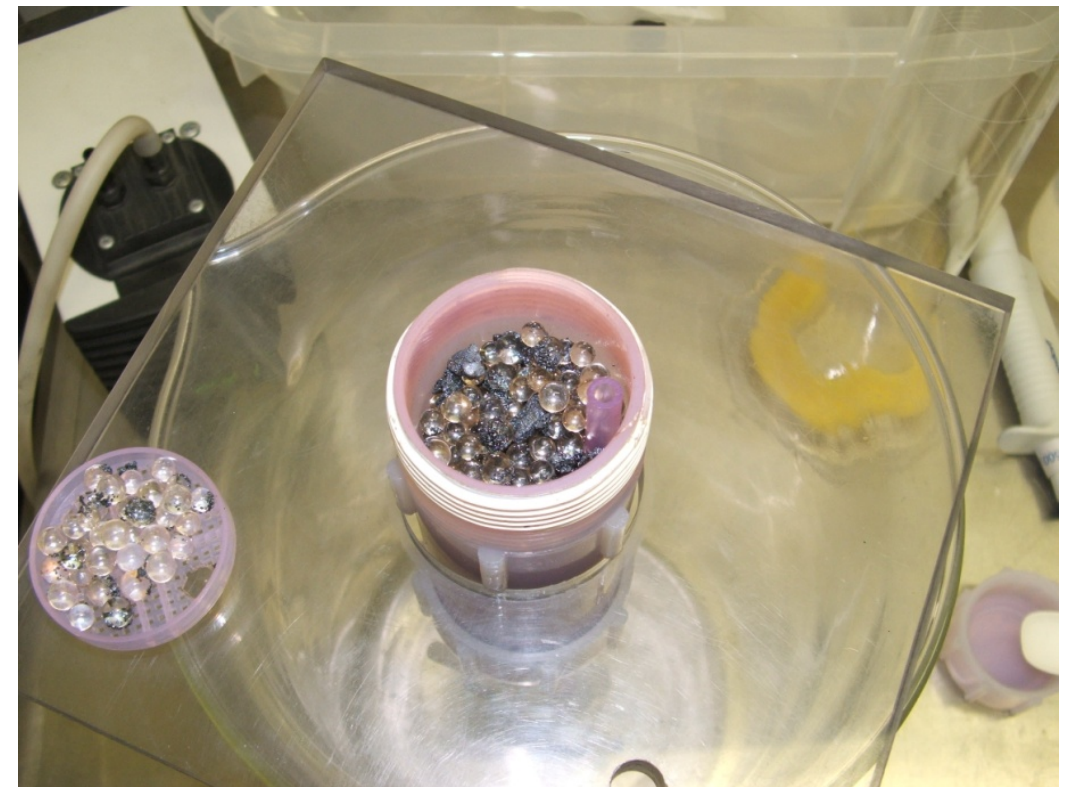

Figure 2-4. Opened iodine generator showing the glass beads and iodine crystals dispersed among the glass beads.

\subsubsection{Humidifier}

Humidified air was produced by passing air or nitrogen through a fritted glass bubbler submerged in a constant temperature bath. A thermocouple in the headspace of the bubbler provided the temperature of the water-saturated gas. The concentration of water in the blended gas was controlled by adjusting the gas flowrate through the humidifier and the humidifier operating temperature.

\subsection{Sorbent Bed Segments}

Figures 2-5 and 2-6 show the detail of the sorbent beds and how the beds are configured in a temperature-controlled oven.

\subsection{Sample Collection and Analysis}

Iodine and methyl iodide concentrations in the process gas can be measured at up to five locations in the test system - at the inlet to the sorbent bed segments, and at the outlet of each of the four bed segments. Since the gas flowrate is essentially the same at all five sample locations, the removal efficiencies for the sorbent in all four beds can be determined by measuring the iodine and methyl iodide concentrations at these locations. By integrating over time and using the process flowrate, the amounts of iodine and methyl iodide adsorbed on each of the beds can be calculated. 


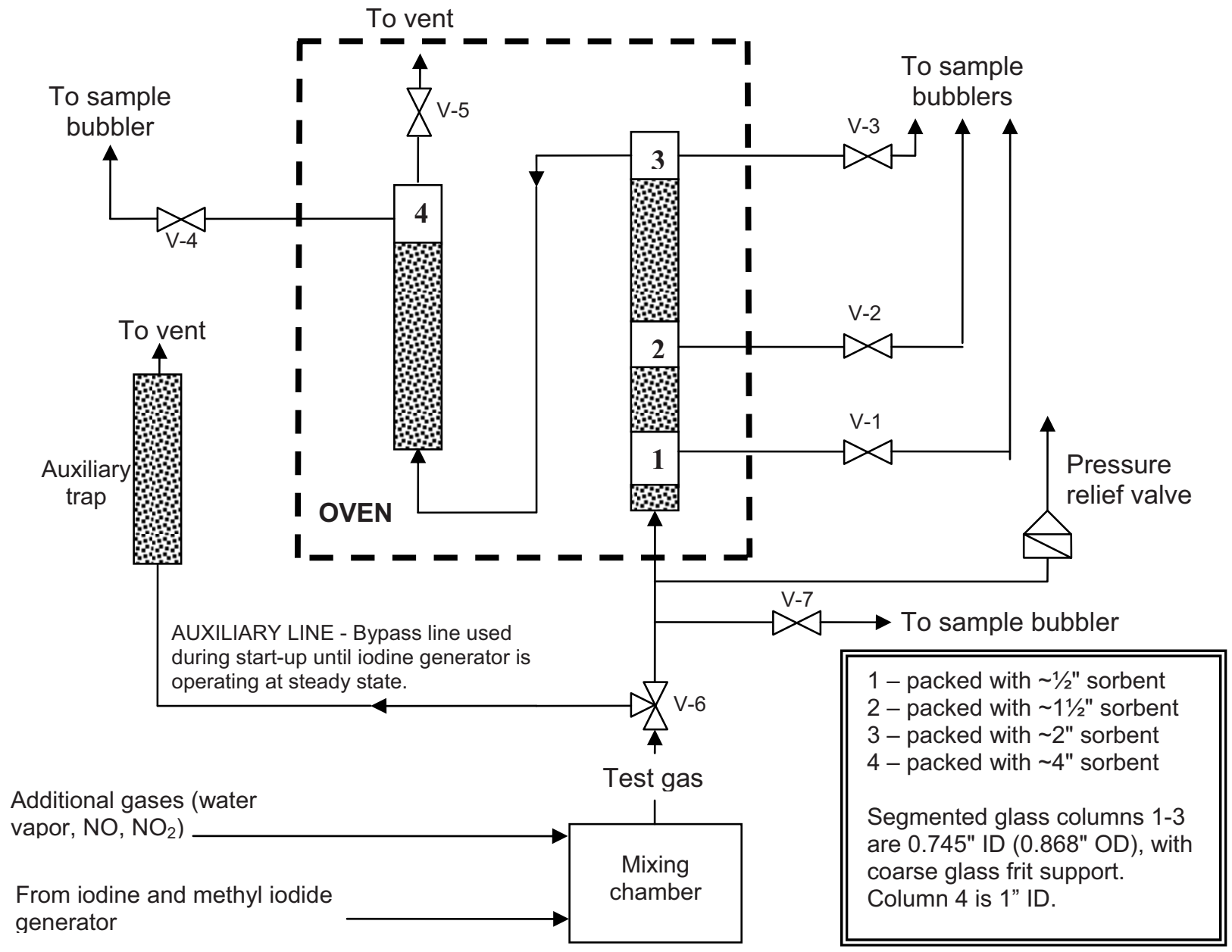

Figure 2-5. Detail of the sorbent beds. At times, only 3 instead of all 4 beds are used.

\subsection{1 lodine Sample Collection and Analysis}

For measuring the gaseous iodine concentration, the process gas from any of the five sample locations is passed through 25-ml "midget" impingers (shown in Figure 2-2 above) that contain $0.1 \mathrm{~N} \mathrm{NaOH}$ for scrubbing halogen gases including $\mathrm{I}_{2}$ and $\mathrm{HI}$, if present. This technique is modeled after EPA Method 26 "Determination of Hydrogen Halide and Halogen Emissions from Stationary Sources, Non-Isokinetic Method" (40 CFR 60 Appendix A). The caustic solution dissolves halogens by hydrolyzing halogen gases to form a proton $\left(\mathrm{H}^{+}\right)$and hypohalous acid. Any HI, if present, dissolves by dissociating in the caustic solution, and is included with $\mathrm{I}_{2}$ in the analysis.

The typical $\mathrm{NaOH}$ concentration in the $25-\mathrm{ml}$ bubblers has been $0.1 \mathrm{~N}$, as specified in Method 26. This provides orders-of-magnitude safety factors in the absorbing capacity of the solution. We also occasionally check the $\mathrm{pH}$ of the bubbler solutions to verify that the absorbing capability of the solution is not depleted.

The bubbler solutions are analyzed by inductively coupled plasma mass spectrometry (ICP-MS) per EPA Method 6020A (SW-846, "Test Methods for Evaluating Solid Wastes Physical/Chemical Methods," http://www.epa.gov/osw/hazard/testmethods/sw846/online/). We can detect gaseous iodine concentrations as low as $0.08 \mathrm{ppbv}$ with this method. Higher concentration samples for gas streams with 1 ppmv or higher iodine concentrations are typically diluted for analysis. 


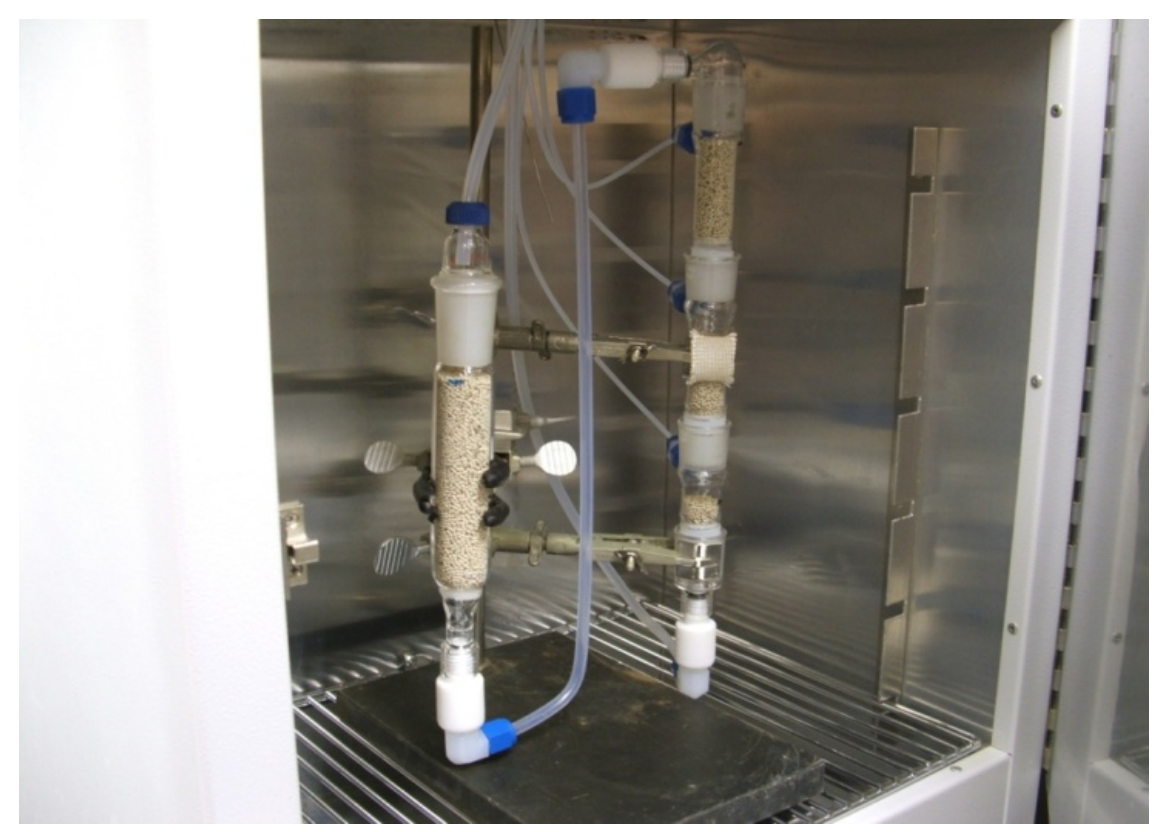

Figure 2-6. Configuration of the sorbent beds inside the temperature-controlled oven.

\subsubsection{Methyl lodide Sampling and Analysis}

Methyl iodide was not used in the tests performed this fiscal year because the gas chromatograph (GC) used to speciate the methyl iodide was malfunctioning. The corrosive iodine process gas streams that, at times, contains $\mathrm{I}_{2}, \mathrm{CH}_{3} \mathrm{I}$, and $\mathrm{NO}_{\mathrm{x}}$, may have damaged one or more of the $\mathrm{GC}$ components. We are presently investigating if the $\mathrm{GC}$ is repairable or if a new $\mathrm{GC}$ will be required.

\subsubsection{Sampling and Analysis Lessons Learned}

Some sampling and analysis lessons have been learned this past year and in prior years:

- When control efficiencies in excess of $1,000 \mathrm{x}$ are measured, the iodine species concentrations in the process gas vary by more than 1,000x. This means that lab equipment such as bubblers, fittings, and tubing that contacts the higher-concentration gas streams and scrubber solutions can often be contaminated with iodine species at levels that are not easily removed without thorough cleaning. Even with multiple rinsing, if impingers used at the higher-concentration-locations are used in subsequent sample collection at the lower-concentration-locations, they can result in highbiased results due to contamination. To minimize the effects of contamination the impingers and fittings used at each of the 5 potential sample locations have been labeled and kept separate.

- The blended gas streams can corrode fittings, tubing, and equipment. The system components must be heated to above dewpoint temperatures to avoid corrosive condensation. System components, in particular for the GC and MS systems, need to be routinely cleaned, maintained, and replaced when necessary.

- Best test results are obtained when sets of samples are collected for analysis at the same time. Each set needs to include the sorbent bed inlet sample and outlet samples from each of the sorbent bed segments. Some variation or drift can occur in the inlet concentrations; obtaining a sample of the inlet gas at the same time the sorbent bed outlet samples are obtained, provides tracking of the inlet gas concentrations should they drift over time. 
- Sorbent bed breakthrough tests sometimes require 10's or 100's of hours. Sample periods may be extended to once every 4 hours or more in such cases to minimize sampling and analysis costs.

- On-line mass spectrometry analysis. We evaluated an on-line mass spectrometer during FY 12 for $\mathrm{I}_{2}, \mathrm{CH}_{3} \mathrm{I}$, and $\mathrm{HI}$ analyses, as an alternative to the $\mathrm{GC}$. We found that the mass spectrometer did not provide sufficiently low detection limits.

- We also evaluated, during FY-12, bubbler methods to capture and speciate organic iodide species. The methods investigated required considerable method development, which was outside the scope of this year's project.

\section{DEEP BED AEROGEL TEST RESULTS}

Results of the first two of three Aerogel tests performed this year have been reported in Soelberg 2012. The complete and updated results are provided here for all three tests. These results supersede the results in Soelberg 2012 because they have been adjusted to reflect the likelihood that the sorbents may not have reached full saturation during the tests.

\subsection{Aerogel Sorbent}

The silver-functionalized Aerogel sorbent was prepared and provided by Pacific Northwest National Laboratory (PNNL). Aerogel is a highly porous solid material produced by replacing the liquid component of a gel (typically silica gel) with a gas. Aerogels have low densities and high surface areas. The silica Aerogel provided by PNNL was functionalized with silver nanoparticles that were produced by reducing the silver thiolate adduct ions at $165^{\circ} \mathrm{C}$ for $2 \mathrm{~h}$ under flowing $2.7 \% \mathrm{H}_{2}$ in Ar. The Brunauer, Emmett, and Teller (BET) surface area is about $200 \mathrm{~m}^{2} / \mathrm{g}$. The bulk density is about $500 \mathrm{~kg} / \mathrm{m}^{3}$. The silver content is estimated at $30 \mathrm{wt} \%$ (30 g silver per $100 \mathrm{gm}$ silver-functionalized Aerogel).

Figure 3-1 shows the as-received silver-functionalized Aerogel received at the Idaho National Laboratory (INL) from PNNL for these tests. The color was a grey-black mix. As the sorbent was exposed to the humidified, $\mathrm{NO}_{\mathrm{x}}$-laden test gas containing iodine, it tended to turn to a mixed rusty-redblack color and then to a grey-yellow-black mixed color (Figure 3-2).
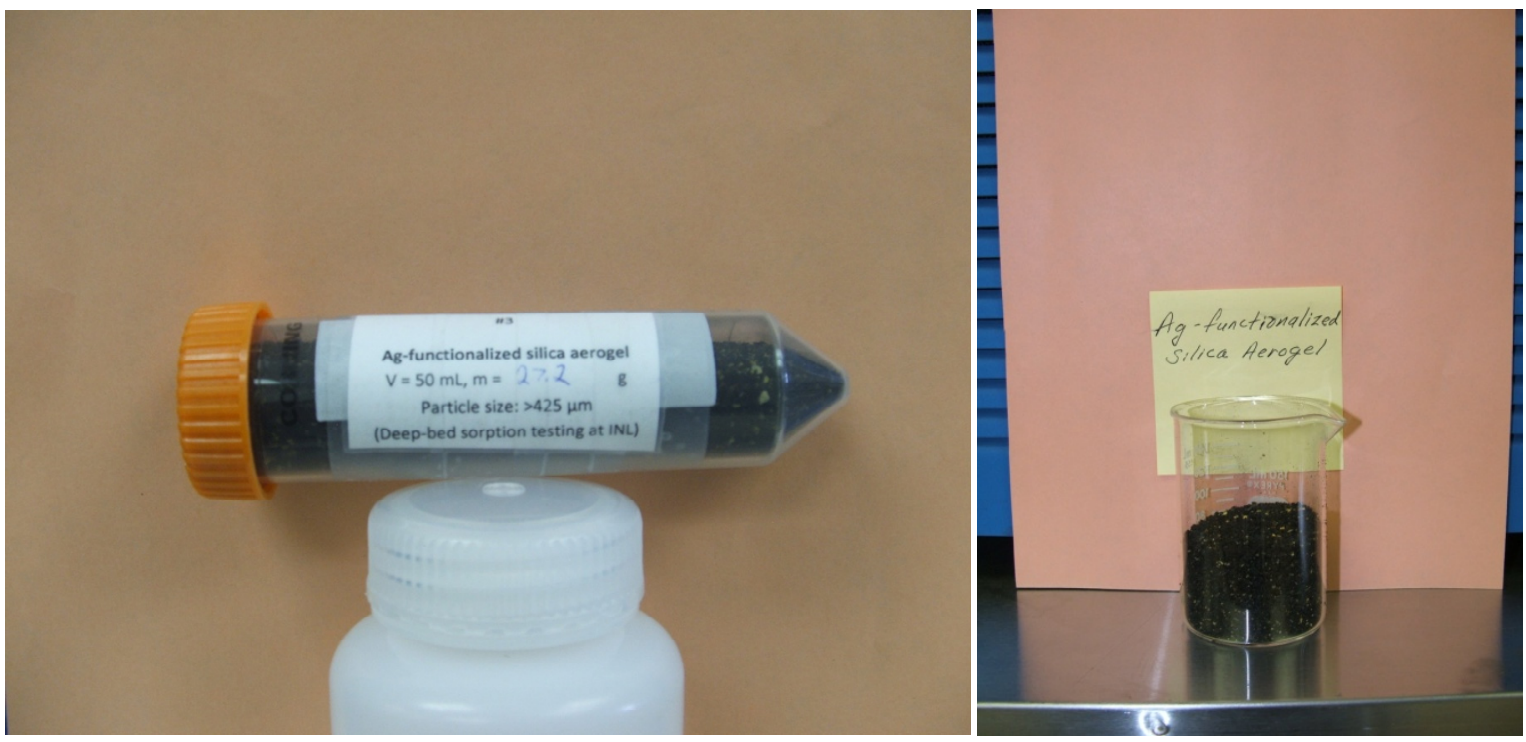

Figure 3-1. As-received silver-functionalized Aerogel from PNNL. 


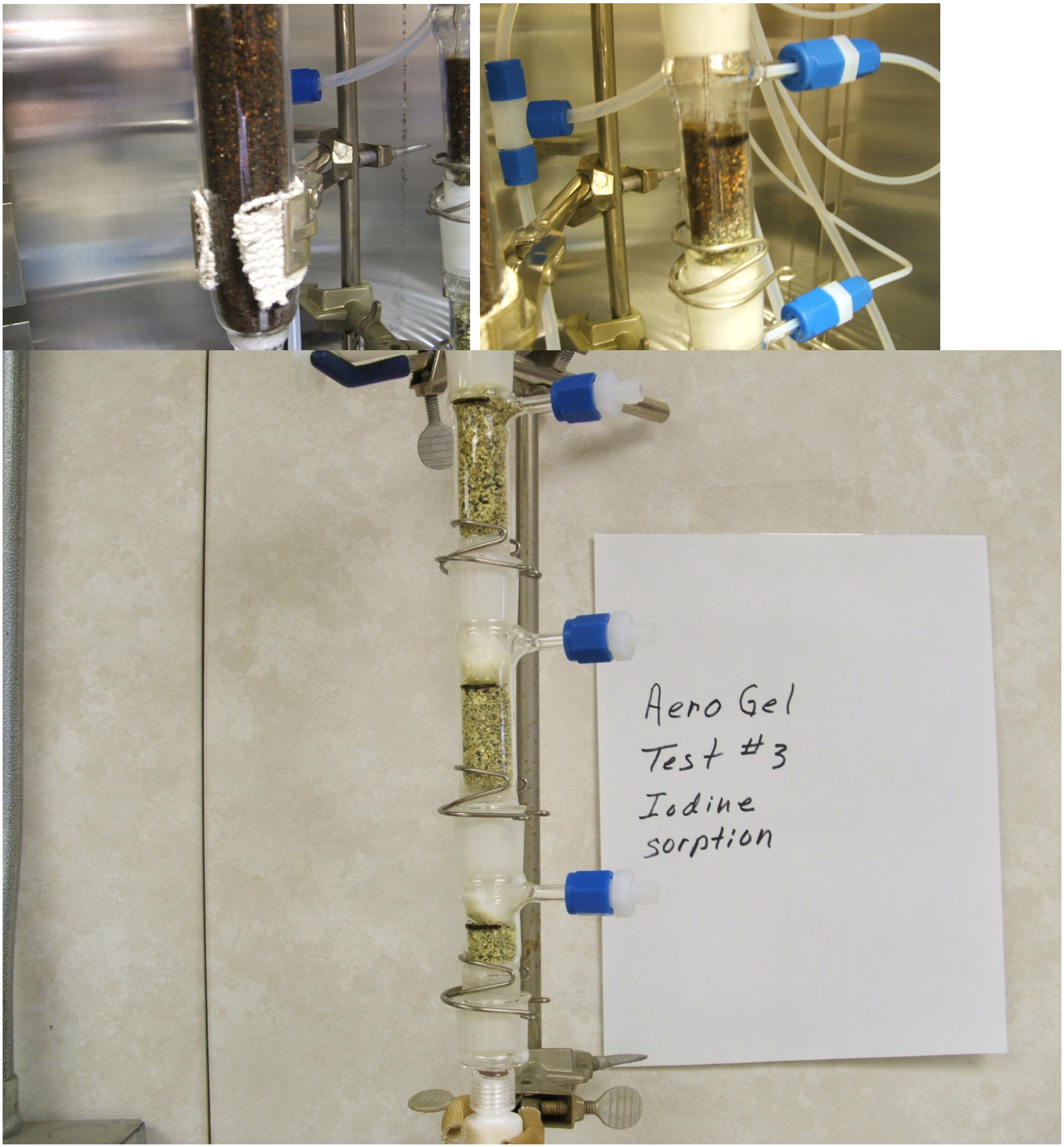

Figure 3-2. Silver-functionalized Aerogel during and after iodine sorption testing. With gas flowing up through the beds, the color gradually changed to a rusty-red-black mix (top left) and then to a greyyellow-black mix (top right and bottom photos).

\subsection{Summary of Aerogel Test Results}

Table 3-1 summarizes the Aerogel adsorption test conditions. The inlet iodine concentration in Test AG-1 averaged $2.0 \mathrm{ppm}$. The inlet iodine concentration in Test AG-2 averaged $34 \mathrm{ppm}$. The inlet iodine concentration in Test AG-3 averaged $8.0 \mathrm{ppm}$. These concentrations were set to provide a range of inlet iodine concentrations, holding all other test conditions constant, to assess the range of potential sorption capacities for different inlet iodine concentrations. 
Table 3-1. Silver-functionalized Aerogel sorption test conditions.

\begin{tabular}{|c|c|c|c|}
\hline Run Number & Test AG-1 & Test AG-2 & Test AG-3 \\
\hline Simulate what off-gas? & dissolver & dissolver & dissolver \\
\hline & 6 Mar to & 23 May to & 9 July to \\
\hline Test dates & 4 Apr 12 & 31 May 12 & 24 July 12 \\
\hline \multicolumn{4}{|l|}{ I2 fixed bed system } \\
\hline Water bath $\mathrm{T}$, deg. $\mathrm{C}$ & 27 & 45 & 35 \\
\hline Carrier gas type & $\mathrm{N} 2$ & N2 & $\mathrm{N} 2$ \\
\hline Carrier gas rate, sccm & 9 & 150 & 100 \\
\hline I2 conc., ppm & 367 & 361 & 172 \\
\hline$\%$ of I 2 saturation level & $60.0 \%$ & $15.0 \%$ & $15 \%$ \\
\hline \multicolumn{4}{|l|}{ Make-up gas system } \\
\hline Gas type & $\mathrm{N} 2$ & $\mathrm{~N} 2$ & $\mathrm{~N} 2$ \\
\hline Gas rate, $\mathrm{sccm}$ & 880 & 740 & 790 \\
\hline \multicolumn{4}{|l|}{ Humidifier system } \\
\hline Humidifer oven $\mathrm{T}$, deg. $\mathrm{C}$ & 31.0 & 31.0 & 31.0 \\
\hline Humidifier oven $\mathrm{P}$, inches $\mathrm{Hg}$ & 25.5 & 25.5 & 25.5 \\
\hline Humidifier saturation efficiency, $\%$ & $95 \%$ & $95 \%$ & $95 \%$ \\
\hline Carrier gas type & $\mathrm{N} 2$ & $\mathrm{~N} 2$ & $\mathrm{~N} 2$ \\
\hline Carrier gas rate, sccm & 500 & 500 & 500 \\
\hline Carrier gas moisture content, vol $\% \mathrm{H} 2 \mathrm{O}$ & 4.8 & 4.8 & 4.8 \\
\hline Total gas flowrate & 525 & 525 & 525 \\
\hline \multicolumn{4}{|l|}{ Other gases } \\
\hline NO ppmv & 10,000 & 10,000 & 10,000 \\
\hline $\mathrm{NO} 2 \mathrm{ppmv}$ & 10,000 & 10,000 & 10,000 \\
\hline NO gas rate, $\mathrm{sccm}$ & 135 & 135 & 135 \\
\hline NO2 gas rate, $\mathrm{sccm}$ & 135 & 135 & 135 \\
\hline \multicolumn{4}{|l|}{ Sorption conditions } \\
\hline Temperature, deg. $\mathrm{C}$ & 150 & 150 & 150 \\
\hline Total gas flowrate, sccm & 1,684 & 1,685 & 1,685 \\
\hline Target $I 2$ conc, ppmv & 2.0 & 32 & 10.2 \\
\hline Measured $I 2$ conc, $p p m v$ & 2.0 & 34 & 8.0 \\
\hline Measured total I flowrate, $\mathrm{mg} / \mathrm{min}$ & 0.035 & 0.60 & 0.14 \\
\hline H2O conc, $\%$ & 1.5 & 1.5 & 1.5 \\
\hline H2O dewpoint, deg. C & 11 & 11 & 11 \\
\hline NO conc., ppmv & 801 & 801 & 801 \\
\hline NO2 conc., ppmv & 801 & 801 & 801 \\
\hline Balance & $\mathrm{N} 2$ & $\mathrm{~N} 2$ & $\mathrm{~N} 2$ \\
\hline Sorption gas velocity, f/min & 10.0 & 10.0 & 10.0 \\
\hline Bed 1 out residence $t$, sec & 0.076 & 0.076 & 0.076 \\
\hline Bed 2 out cumulative residence $t$, sec & 0.31 & 0.30 & 0.30 \\
\hline Bed 3 out cumulative residence $t$, sec & 0.61 & 0.61 & 0.61 \\
\hline Bed 4 out cumulative residence $t$, sec & 1.22 & 1.22 & 1.22 \\
\hline Cumulative test duration, $\mathrm{hr}$ & 242 & 64 & 162 \\
\hline
\end{tabular}

[iodine data 28aug12.xlsx]2012 aerogel test summary

Test durations were estimated based on the timed needed to reach 100\% Ag utilization in Bed 1, for each inlet concentration, with some safety factor for loss of efficiency as the Bed 1 sorbent approached saturation. Silver utilization is defined to be the amount of the initial silver in the sorbent that has reacted with iodine according to the stoichiometry $\mathrm{Ag}+\mathrm{I}=\mathrm{AgI}$.

As it turned out, the results showed that the test durations were not long enough to reach saturation in Bed 1. It appears that the behavior of the MTZ in the Aerogel is somewhat different from the classic MTZ concept shown in Figure 3-3, where the MTZ progresses through the depth of the sorbent bed as 
time progresses and the bed becomes loaded with sorbent. Instead, the behavior of the mass transfer zone is more like that shown in Figure 3-4, where the front of the MTZ progresses through the depth of the bed as it becomes loaded; but the depth of the MTZ actually increases over time, because even the first (0.5inch deep) bed did not appear to reach saturation during the test durations. In this case, the depth of the MTZ increases over time as it progresses through the bed.

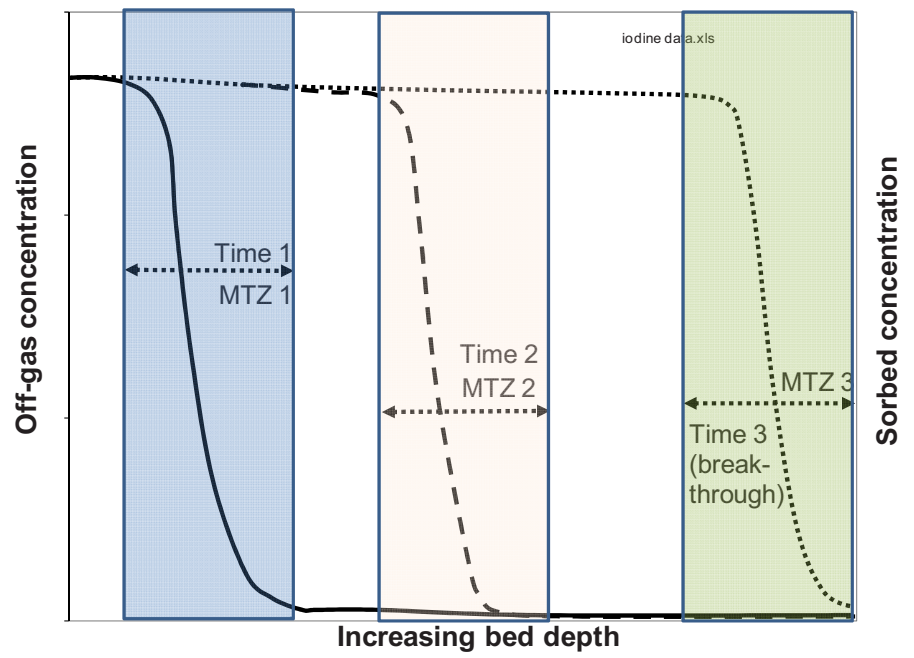

Figure 3-3. Classic mass transfer zone progression through the depth of a fixed bed over time.

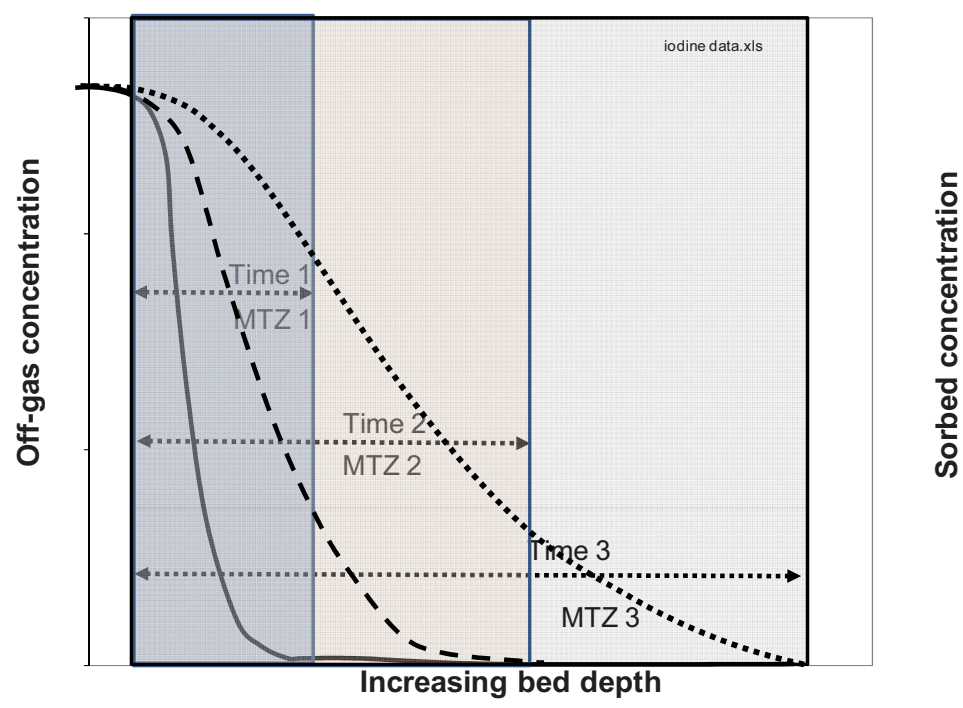

Figure 3-4. Apparent mass transfer zone observed during the deep-bed tests.

Table 3-2 shows the sorbent bed masses and the sorbent loadings measured in two ways. The sorbent loadings were calculated based on weight gain (assuming that any weight change of the sorbent before and after a test is due to the sorption of iodine), and also based on the bed inlet and outlet gaseous iodine measurements. The difference between the measured gaseous iodine is attributed to the amount that adsorbed in each bed. Sorbent loadings determined from the gas-phase measurements were higher than loadings determined from the weight gain. 
The sorbent loadings determined from the gas-phase measurements also increased with increasing inlet iodine concentration, as shown in Figure 3-5. Indeed, when the inlet iodine concentration averaged $34 \mathrm{ppm}$ for Test AG-2, the calculated silver utilization reached 130\% (but was only $47 \%$ determined gravimetrically). We recommend performing additional analyses, in particular iodine concentration in the sorbents, to better assess the differences in the gravimetric and gas-phase analysis methods of sorbent loading.

Table 3-2. Silver-functionalized Aerogel sorption test results.

\begin{tabular}{|c|c|c|c|c|c|c|}
\hline Run Number & \multicolumn{2}{|c|}{ Test AG-1 } & \multicolumn{2}{|c|}{ Test AG-2 } & \multicolumn{2}{|c|}{ Test AG-3 } \\
\hline Simulate what off-gas? & \multicolumn{2}{|c|}{ dissolver } & \multicolumn{2}{|r|}{ dissolver } & \multicolumn{2}{|c|}{ Dissolver } \\
\hline wt\% silver & \multicolumn{2}{|r|}{$30 \%$} & \multicolumn{2}{|r|}{$30 \%$} & \multicolumn{2}{|r|}{$30 \%$} \\
\hline Pretest mass, Bed 1, g & \multicolumn{2}{|r|}{2.13} & \multicolumn{2}{|r|}{2.10} & \multicolumn{2}{|r|}{2.28} \\
\hline Pretest mass, Bed 2, g & \multicolumn{2}{|r|}{6.4} & \multicolumn{2}{|r|}{6.58} & \multicolumn{2}{|r|}{7.18} \\
\hline Pretest mass, Bed 3, g & \multicolumn{2}{|r|}{8.34} & \multicolumn{2}{|r|}{9.20} & \multicolumn{2}{|r|}{9.29} \\
\hline Pretest mass, Bed 4, g & \multicolumn{2}{|r|}{26.78} & \multicolumn{2}{|r|}{0} & \multicolumn{2}{|r|}{0} \\
\hline Pretest total mass, Total, $\mathrm{g}$ & \multicolumn{2}{|r|}{43.65} & \multicolumn{2}{|r|}{17.88} & \multicolumn{2}{|r|}{18.75} \\
\hline Post-test mass, Bed 1, g & \multicolumn{2}{|r|}{2.37} & \multicolumn{2}{|r|}{2.45} & \multicolumn{2}{|r|}{2.74} \\
\hline Post-test mass, Bed 2, g & \multicolumn{2}{|r|}{6.53} & \multicolumn{2}{|r|}{7.48} & \multicolumn{2}{|r|}{8.36} \\
\hline Post-test mass, Bed 3, g & \multicolumn{2}{|r|}{8.02} & \multicolumn{2}{|r|}{9.57} & \multicolumn{2}{|r|}{10.76} \\
\hline Post-test mass, Bed 4, g & \multicolumn{2}{|r|}{27.53} & & 0 & & 0 \\
\hline Post-test total mass, Total, g & & 44.45 & & 19.50 & & 21.86 \\
\hline delta mass, Bed 1, $g$ & & 0.24 & & 0.35 & & 0.46 \\
\hline delta mass, Bed 2, g & & 0.13 & & 0.90 & & 1.18 \\
\hline delta mass, Bed 3, $g$ & & -0.32 & & 0.37 & & 1.47 \\
\hline delta mass, Bed 4, $g$ & & 0.75 & & 0 & & 0 \\
\hline delta mass, total, $g$ & & 0.8 & & 1.62 & & 3.11 \\
\hline & $\begin{array}{c}\text { From } \\
\text { weight } \\
\text { gain } \\
\end{array}$ & $\begin{array}{c}\text { From in and } \\
\text { out iodine gas } \\
\text { measurements }\end{array}$ & $\begin{array}{c}\text { From } \\
\text { weight } \\
\text { gain } \\
\end{array}$ & $\begin{array}{c}\text { From in and } \\
\text { out iodine gas } \\
\text { measurements }\end{array}$ & $\begin{array}{c}\text { From } \\
\text { weight } \\
\text { gain } \\
\end{array}$ & $\begin{array}{c}\text { From in and } \\
\text { out iodine gas } \\
\text { measurements }\end{array}$ \\
\hline Iodine loading on Bed 1, wt $\%$ & $11 \%$ & $20 \%$ & $17 \%$ & $46 \%$ & $20 \%$ & $22 \%$ \\
\hline Iodine loading on Bed 2, wt $\%$ & $2.0 \%$ & $1.4 \%$ & $14 \%$ & $14 \%$ & $16 \%$ & $5 \%$ \\
\hline Silver utilization, mole $\%$, Bed 1 & $32 \%$ & $58 \%$ & $47 \%$ & $130 \%$ & $57 \%$ & $63 \%$ \\
\hline Silver utilization, mole $\%$, Bed 2 & $5.8 \%$ & $4.0 \%$ & $39 \%$ & $40 \%$ & $47 \%$ & $13 \%$ \\
\hline
\end{tabular}

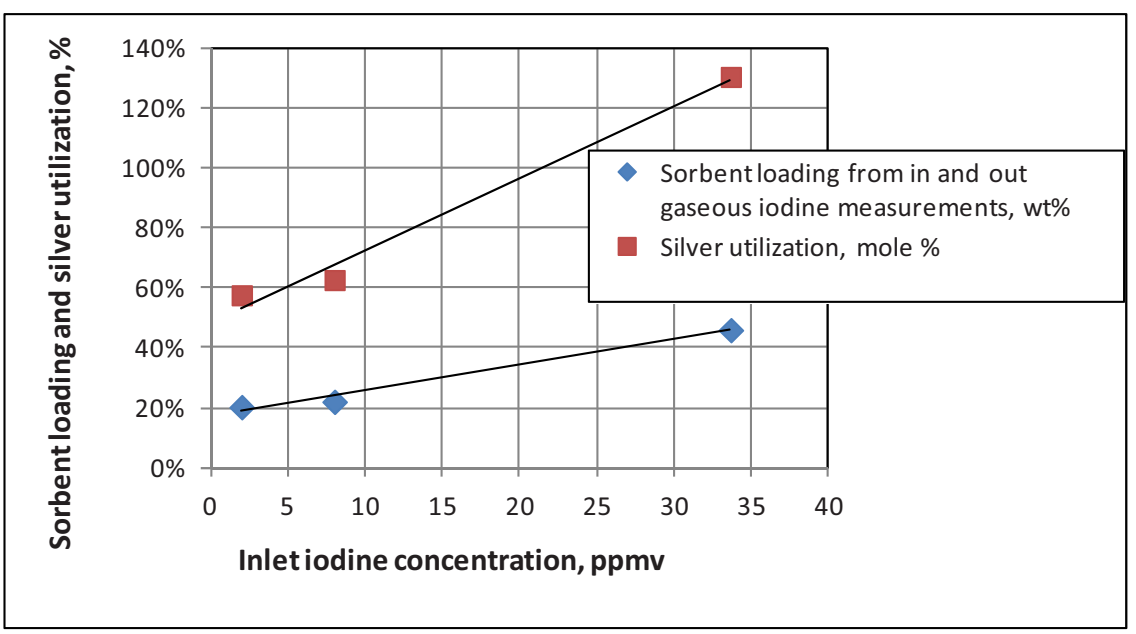

Figure 3-5. Maximum sorbent loadings based on the inlet and outlet gas iodine concentrations for different inlet gas iodine concentrations. 


\subsection{Test AG-1 lodine Sorption Results}

Figure 3-6 shows the trends in gaseous iodine concentrations, decontamination factors (DFs), and silver utilization on Bed 1 during the 242 hour Test AG-1. The DF is the ratio of the inlet and outlet iodine concentrations. This figure shows that:

- The initial Bed 1 DF was about 10,000 (about $1 / 2$ of the DFs observed for Beds 2 and 3), and the Bed 1 DF rapidly dropped within the first 5 hours of the test. This indicates that, under the test conditions, the mass transfer zone was at least 0.5 inches deep at the start of the test.

- Since the measured Bed 1 DF never decreased to 1, some iodine capture was still occurring even after test operation for 242 hours. This suggests that as the test proceeds, the depth of the mass transfer zone increased because even the sorbent in Bed 1 continued to adsorb iodine.

- Iodine DFs in Beds 2 and 3 generally ranged between 20,000 to 40,000 for most of the test. Variations occur in the Bed 2 and 3 DFs because they depend largely on bed outlet iodine concentrations that are at or near the detection limits. The Bed 2 DF began to consistently drop below 10,000 after about hour 200, suggesting that breakthrough had occurred. The long time it took for consistent breakthrough of Bed 2 to occur indicates that the depth of the mass transfer zone was less than the total depth of Beds 1 and 2 ( 2 inches), for the first 200 hours of the test. Breakthrough of Bed 3 was not observed during the duration of this test, indicating the depth of the mass transfer zone did not increase beyond the cumulative depth of Beds 1, 2 and 3 (4 inches) during this test.

- Although Bed 1 approached saturation levels of iodine during this test, Beds 2 and 3 did not reach saturation during this test, even though breakthrough appears to have occurred in Bed 2.

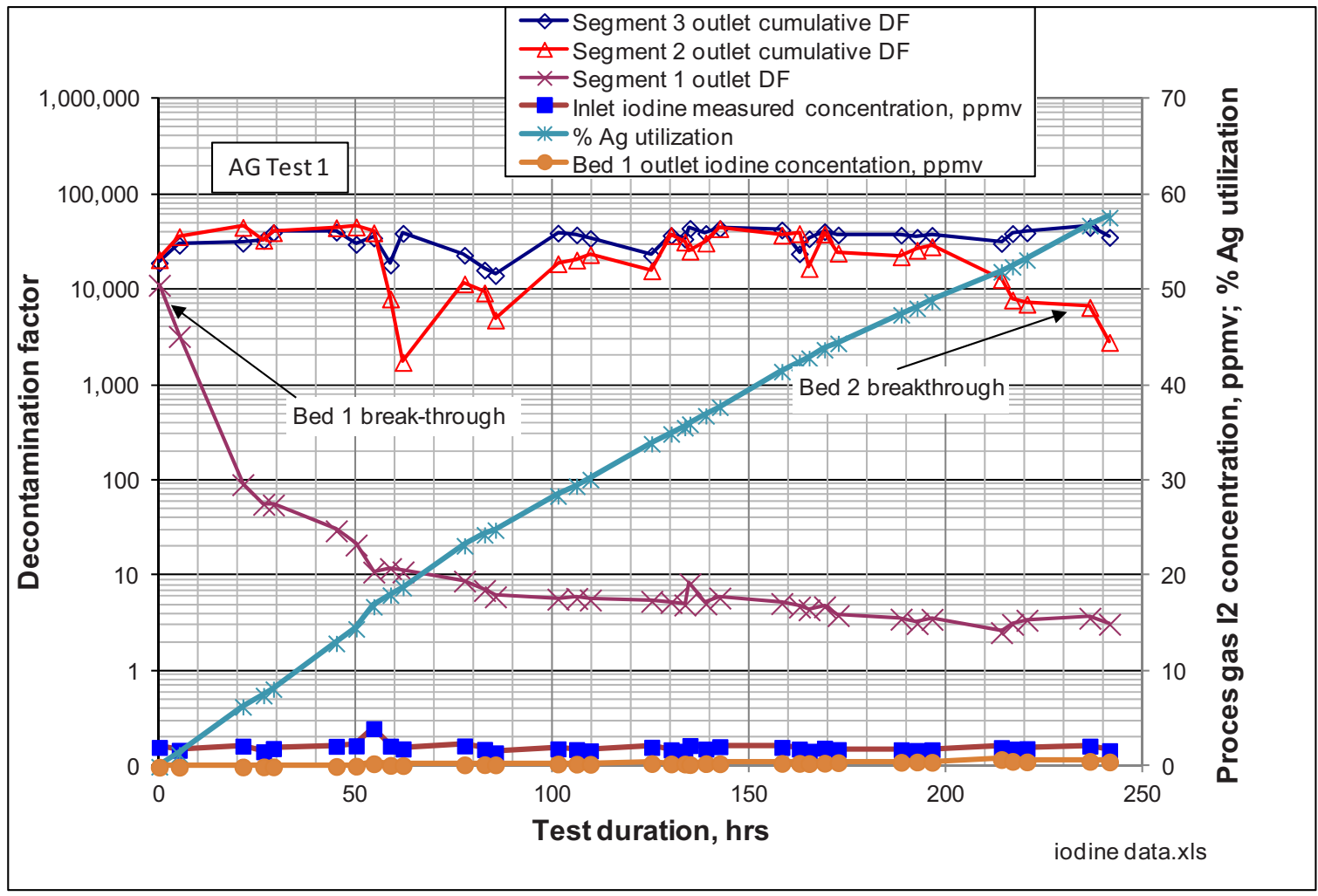

Figure 3-6. Test AG-1 iodine sorption results. 
After each test, the sorbent beds are purged with pure $\mathrm{N}_{2}$ to desorb any amounts of iodine that may be physisorbed. The purge results for Test AG-1 are shown in Figure 3-7. This figure shows that only a small fraction of the iodine adsorbed on Bed 1 was desorbed during the 31-hr purge period. At the start of the purge period, the Bed 1 outlet iodine level was over two orders of magnitude lower than the $\sim 1.6$ ppm range that occurred near the end of the sorption test. This concentration further decreased over another order of magnitude, to essentially the detection limit of the analysis method, after 5 hours of purging. The amount of iodine that was desorbed from Bed 1 started out within the first purge hour at about $0.0002 \%$ of the iodine adsorbed on Bed 1 . After 31 purge hours, the cumulative amount of iodine desorbed from Bed 1 increased to about $0.003 \%$ of the adsorbed iodine, but the increase in desorbed iodine has nearly flattened by that time.

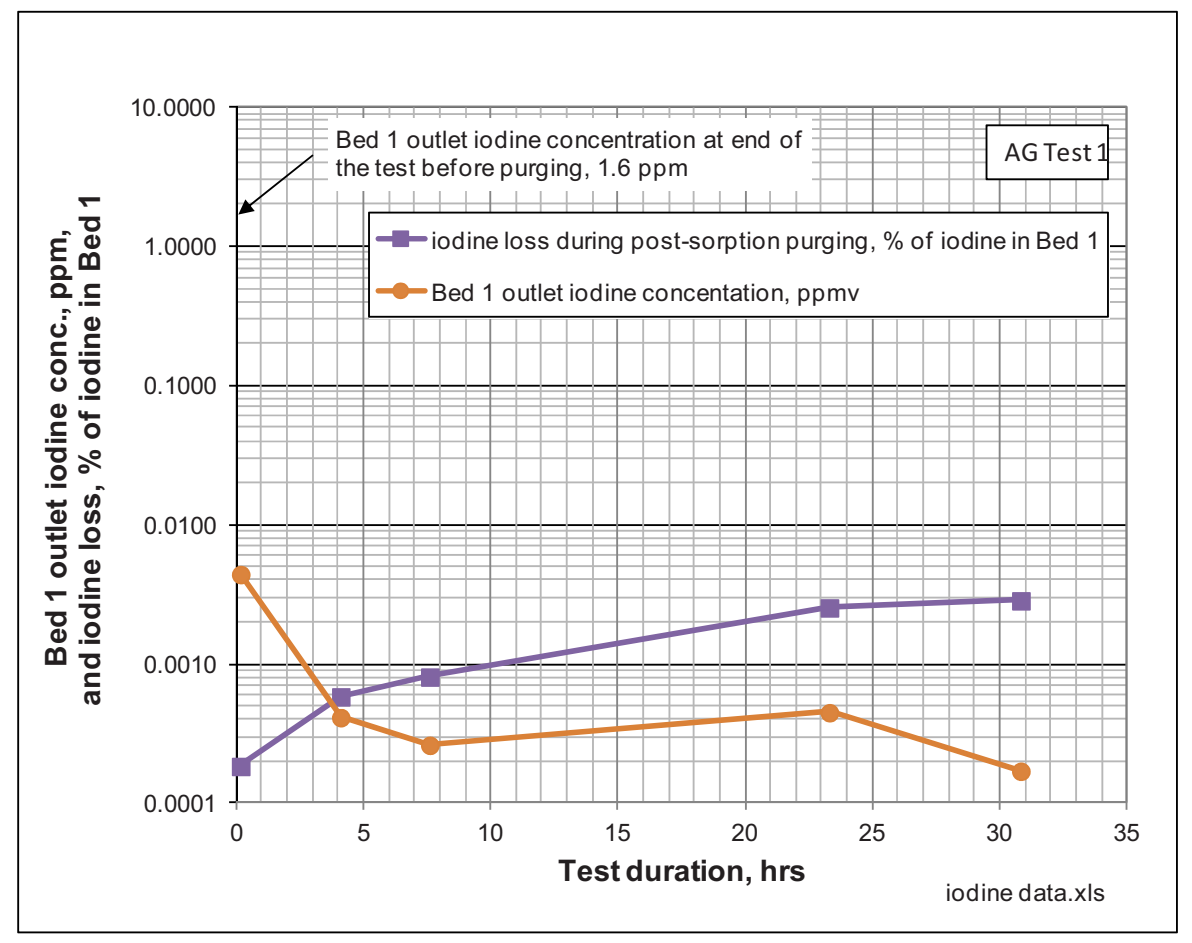

Figure 3-7. Test AG-1 purge results.

The iodine that desorbed from Bed 1 during the purge period was adsorbed in Beds 2 and 3, because shortly after purging was started, the iodine levels at the outlet of beds 2 and 3 had approached the detection limits. This is a likely trend that would occur in a full-scale process - as long as the full depth of a sorbent bed is not saturated, the remaining unsaturated sorbent can serve as a "getter" for physisorbed iodine that may slowly desorb from saturated sorbent pellets. The end result might possibly be efficient retention of the physisorbed iodine as it migrates from physisorption sites into sites were the iodine can chemisorb via reaction with the silver.

\subsection{Test AG-2 lodine Sorption Results}

Figure 3-8 shows the trends in gaseous iodine concentrations, DFs, and silver utilization on Bed 1 during the 64 hour Test AG-2. This figure shows that:

- The initial Bed 1 DF was over 10,000, essentially equal to that of the Bed 2. However, the DF for both Beds 1 and 2 rapidly decreased. This indicates that, under the test conditions, the mass transfer zone was at least 2 inches deep.

- Iodine DFs in Bed 3 generally ranged as high as 20,000 for most of the test, until breakthrough occurred after hour 40. The long time it took for breakthrough of Bed 3 to occur indicates that 
the mass transfer zone was less than the cumulative depth of Beds 1, 2 and 3 (4 inches) for these test conditions up until hour 40.

- According to the Bed 1 outlet iodine measurements, the Bed 1 appears to have gradually approached to near saturation during this test duration, with Bed 1 DFs decreasing to less than 2.

- Beds 2 and 3 did not reach saturation during this test.

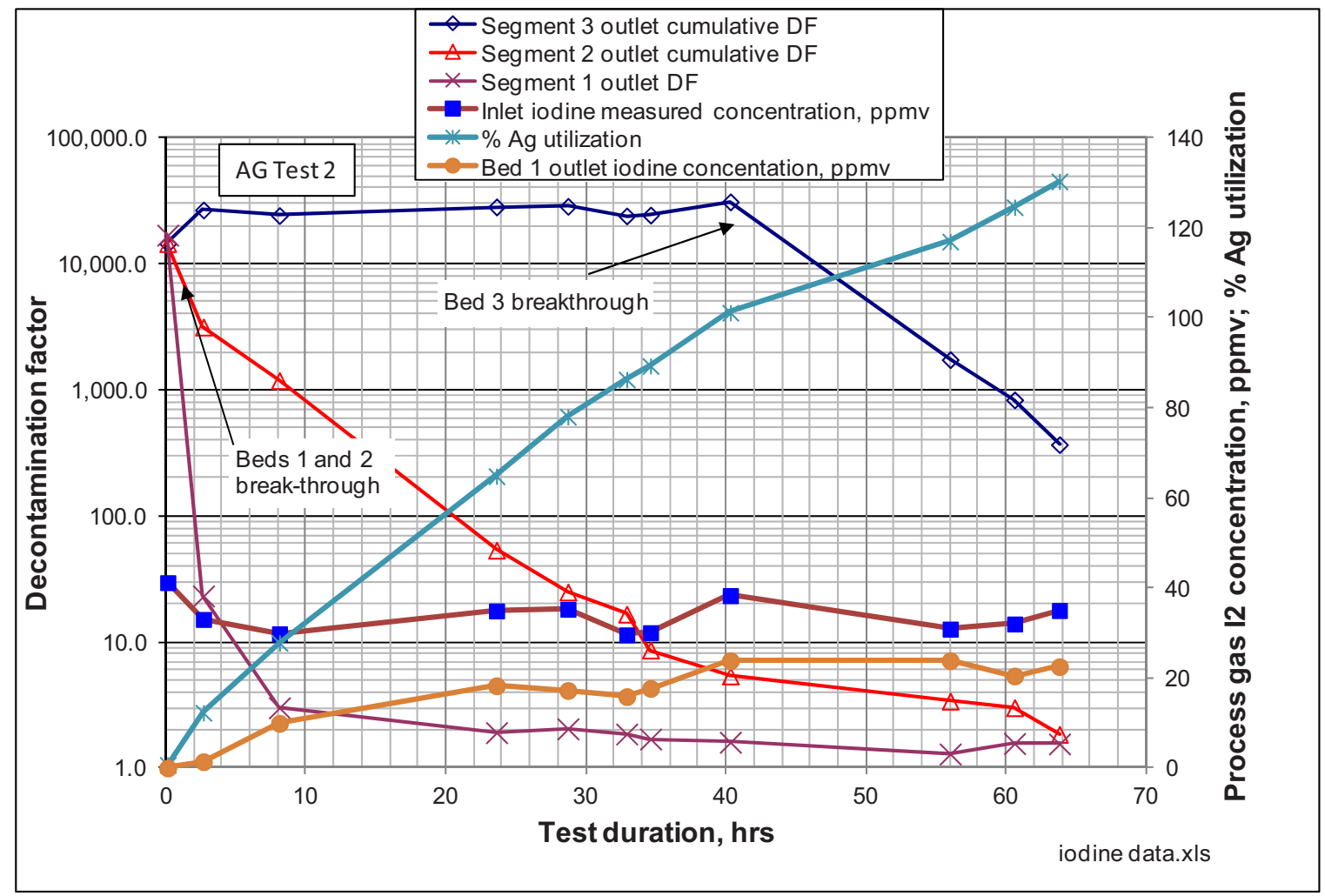

Figure 3-8. Test AG-2 iodine sorption results.

The purge results for Test AG-2 are shown in Figure 3-9. At the start of the purge period, the Bed 1 outlet iodine level was over two orders of magnitude lower than the $31 \mathrm{ppm}$ measured at the end of the sorption test. This concentration further decreased over another order of magnitude, to essentially the detection limit of the analysis method, after 15 hours of purging. The amount of iodine that was desorbed from Bed 1 started out within the first purge hour at under $0.001 \%$ of the iodine adsorbed on Bed 1 . After 24 purge hours, the cumulative amount of iodine desorbed from Bed 1 increased to about $0.004 \%$ of the adsorbed iodine, but the increase in desorbed iodine has nearly flattened by that time.

The iodine that desorbed from Bed 1 during the purge period was adsorbed in Beds 2 and 3, because shortly after purging was started, the iodine levels at the outlet of beds 2 and 3 had approached the detection limits. This is a likely trend that would occur in a full-scale process - as long as the full depth of a sorbent bed is not saturated, the remaining unsaturated sorbent can serve as a "getter" for physisorbed iodine that may slowly desorb from saturated sorbent pellets. The end result might possibly be efficient retention of the physisorbed iodine as it migrates from physisorption sites into sites were the iodine can chemisorb via reaction with the silver. 


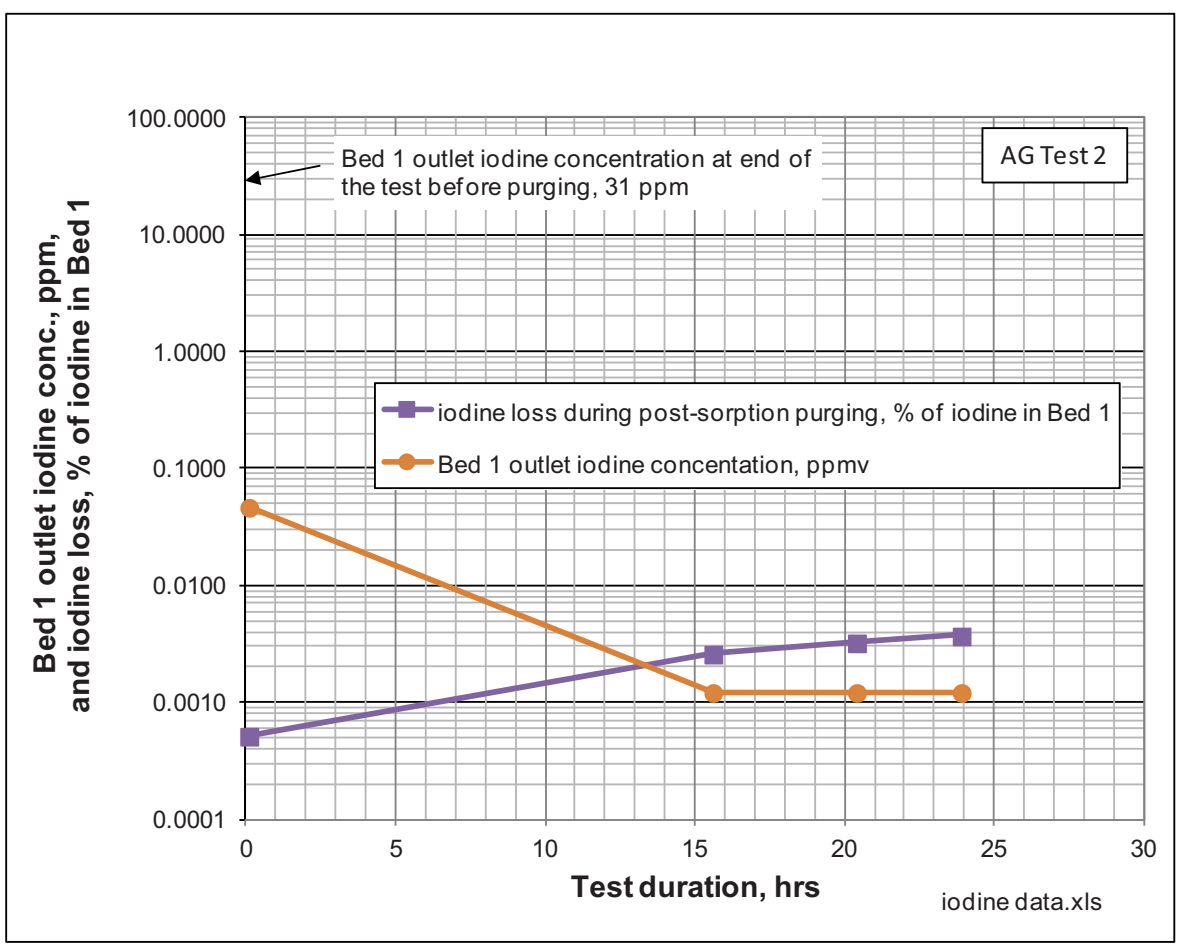

Figure 3-9. Test AG-2 purge results.

\subsection{Test AG-3 lodine Sorption Results}

Figure 3-10 shows the trends in gaseous iodine concentrations, DFs, and silver utilization on Bed 1 during the 162 hour Test AG-3. This figure shows that:

- The initial Bed 1 DF was under 10,000 after only 0.2 hours, and decreased three orders of magnitude in the first 6.5 hours, indicating nearly immediate breakthrough.

- Iodine DFs in beds 2 and 3 generally ranged up to over 100,000 (due in part to exceptionally low ICP-MS sample analysis detection limits for that run) early in the test. Between 6.5 and 23 hours, the Bed 2 reached breakthrough, and after 32-48 hrs, the Bed 3 reached breakthrough. The long time it took for breakthrough of Bed 3 to occur indicates that the mass transfer zone was less than the cumulative depth of Beds 1, 2 and 3 (4 inches) for these test conditions until between hours $32-48$.

- According to the Bed 1 outlet iodine measurements, the Bed 1 appears to have gradually approached to near saturation during this test duration, with DFs less than 2.

- Beds 2 and 3 did not reach saturation during this test, with DFs of around 3 for both beds at the end of the test.

The purge results for Test AG-3 are shown in Figure 3-11. Like the other Aerogel tests, only a small amount, up to about $0.005 \%$ of the adsorbed iodine, was desorbed during the purge period. 


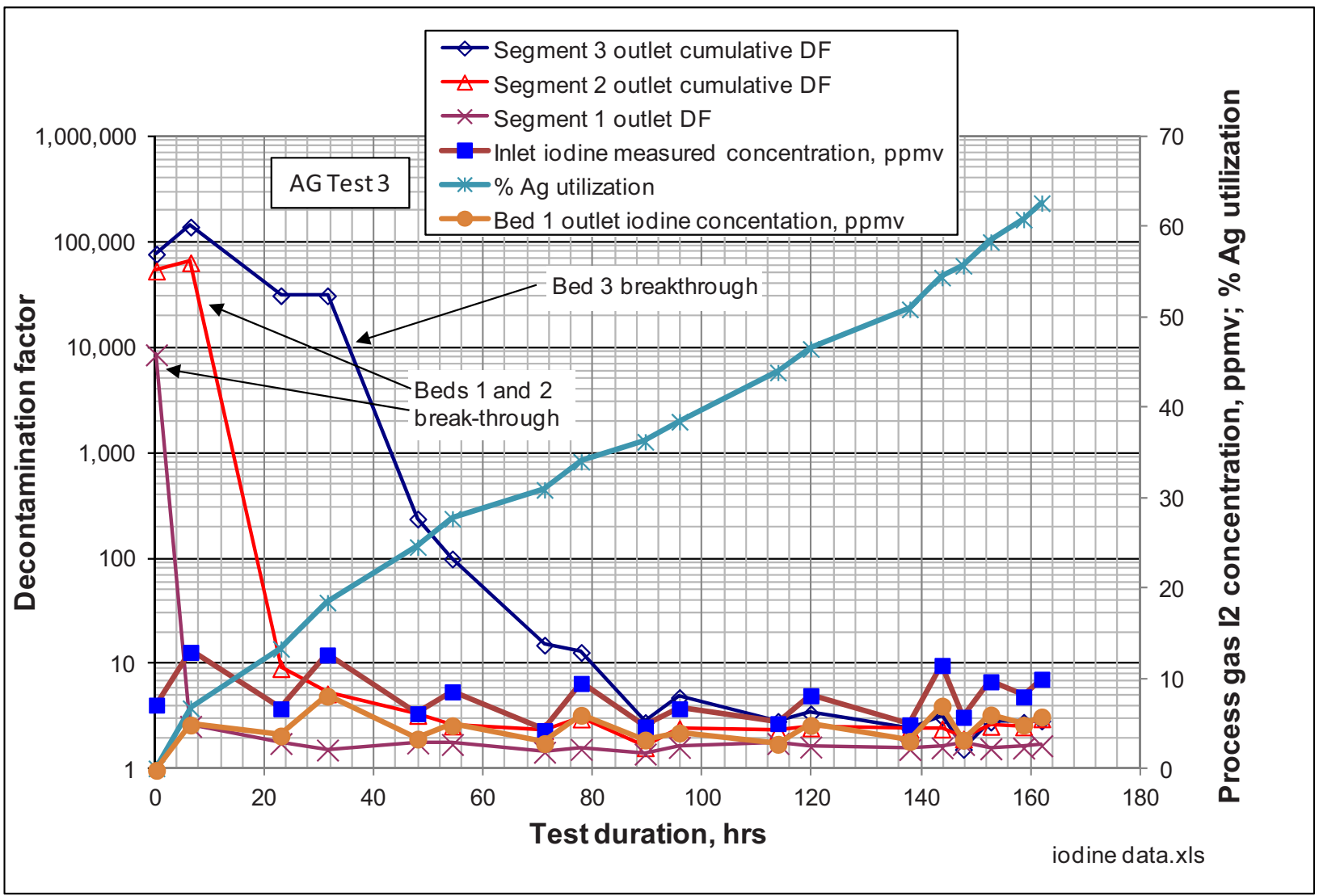

Figure 3-10. Test AG-3 iodine sorption results.

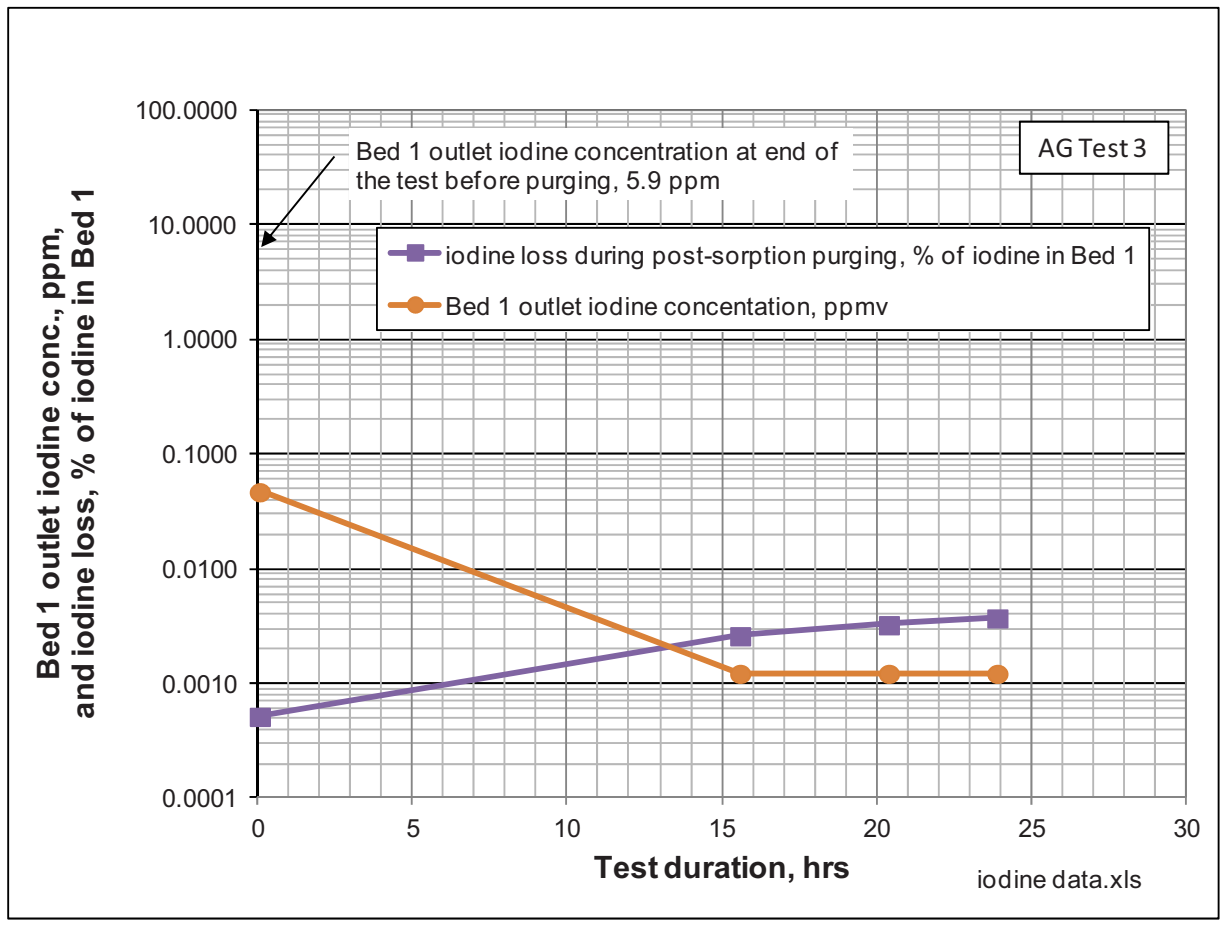

Figure 3-11. Test AG-3 purge results. 


\section{DEEP BED SILVER ZEOLITE TEST RESULTS}

Six tests of hydrogen-reduced silver zeolite (AgZ) were performed in Fiscal Year 2012. The reduced AgZ was provided to the INL by Oak Ridge National Laboratory (ORNL). Figure 4-1 shows the asreceived $\mathrm{AgZ}$ in three sorbent bed columns. The sorbent is in the form of dark grey-black pellets. After the $\mathrm{AgZ}$ was exposed to the humidified, $\mathrm{NO}_{\mathrm{x}}$-laden test gas containing iodine, it tended to turn to a yellow-beige mixed color (Figure 4-2).

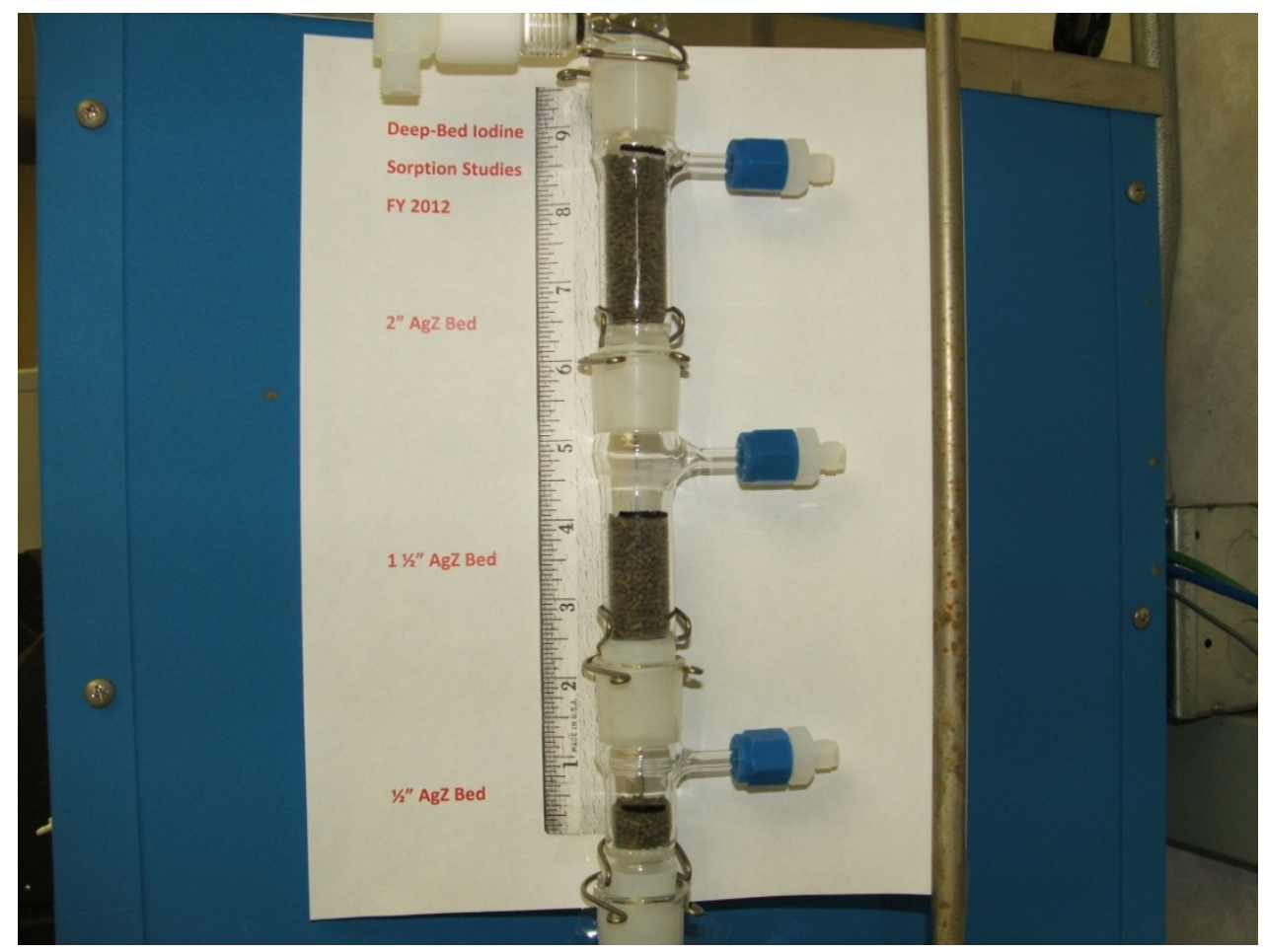

Figure 4-1. As-received AgZ from ORNL.

\subsection{Summary of AgZ Test Results}

Table 4-1 summarizes the AgZ sorption test conditions. The inlet iodine concentrations ranged from 1.6 to 49 ppmv, in mixtures of $\mathrm{N}_{2}, \mathrm{H}_{2} \mathrm{O}$, and $\mathrm{NO}_{\mathrm{x}}$. The iodine concentration was the only parameter in these tests that was varied, to provide data for evaluation in iodine sorption modeling.

Test durations were estimated based on the timed needed to reach 100\% Ag utilization in Bed 1, for each inlet concentration, with some safety factor for loss of efficiency as the Bed 1 sorbent approached saturation. Silver utilization is defined to be the amount of the initial silver in the sorbent that has reacted with iodine according to the stoichiometry Ag $+\mathrm{I}=\mathrm{AgI}$.

As it turned out, the results showed that the test durations were not long enough to reach saturation in Bed 1 in most cases, similar to the Aerogel test results. The behavior of the MTZ in the AgZ appears to be similar to that described in Section 3 for the Aerogel - the front of the MTZ progresses through the depth of the bed as it becomes loaded; and the depth of the MTZ actually increases over time, because even the first (0.5-inch deep) bed did not appear to reach saturation during the tests. 


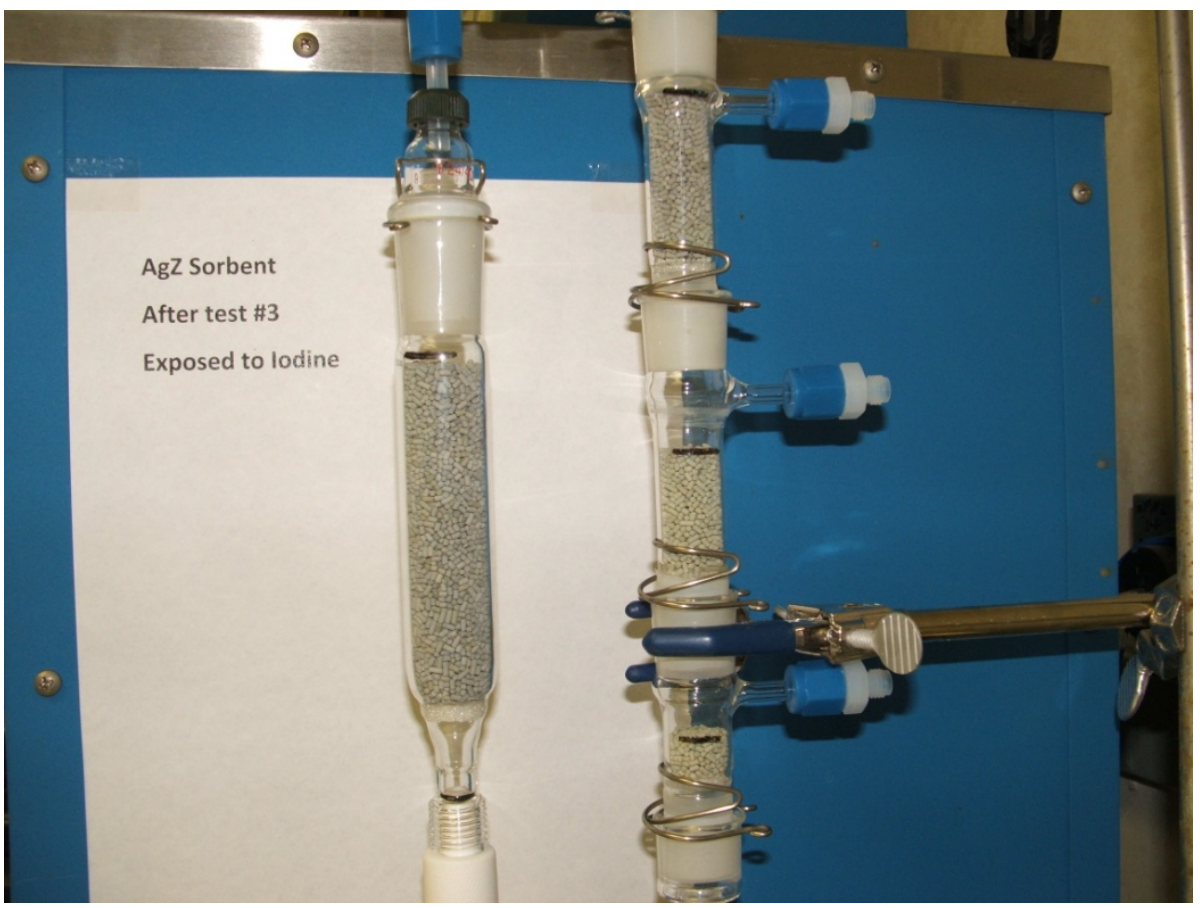

Figure 4-2. AgZ after iodine sorption testing. The dark grey-black color has turned to a yellow-beige color.

Table 4-2 shows the sorbent bed masses and the sorbent loadings measured using the weight gain and also using the bed inlet and outlet gaseous iodine concentrations. The difference between the measured inlet and outlet gaseous iodine is attributed to the amount that adsorbed in each bed. Maximum sorbent loadings determined from the gas-phase measurements were typically higher than loadings determined from the weight gain.

The sorbent loadings determined from the gas-phase measurements tended to increase only slightly with increasing inlet iodine concentration, as shown in Figure 4-3. We recommend performing additional analyses, in particular iodine concentration in the sorbents, to better assess the differences in the gravimetric and gas-phase analysis methods of sorbent loading. 
Table 4-1. AgZ sorption test conditions.

\begin{tabular}{|c|c|c|c|c|c|c|}
\hline Run Number & Test AgZ-1 & Test AgZ-2 & Test AgZ-3 & T est AgZ-6 & Test AgZ-5 & Test AgZ-4 \\
\hline Simulate what off-gas? & dissolver & dissolver & dissolver & dissolver & dissolver & dissolver \\
\hline \multicolumn{7}{|l|}{ I2 fixed bed system } \\
\hline Water bath $\mathrm{T}$, deg. $\mathrm{C}$ & 27 & 35 & 45 & 45 & 45 & 50 \\
\hline Carrier gas type & $\mathrm{N} 2$ & $\mathrm{~N} 2$ & N2 & $\mathrm{N} 2$ & $\mathrm{~N} 2$ & $\mathrm{~N} 2$ \\
\hline Carrier gas rate, $\mathrm{sccm}$ & 9 & 22 & 50 & 50 & 150 & 200 \\
\hline I2 conc., ppm & 183 & 229 & 361 & 361 & 361 & 513 \\
\hline$\%$ of I 2 saturation level & $30 \%$ & $20 \%$ & $15 \%$ & $15 \%$ & $15 \%$ & $15 \%$ \\
\hline \multicolumn{7}{|l|}{ Make-up gas system } \\
\hline Gas type & N2 & N2 & N2 & $\mathrm{N} 2$ & $\mathrm{~N} 2$ & N2 \\
\hline Gas rate, $\mathrm{sccm}$ & 880 & 870 & 840 & 840 & 740 & 690 \\
\hline \multicolumn{7}{|l|}{ Humidifier system } \\
\hline Humidifer oven $\mathrm{T}$, deg. $\mathrm{C}$ & 31 & 31 & 31 & 31 & 31 & 31 \\
\hline Humidifier oven $\mathrm{P}$, inches $\mathrm{Hg}$ & 25.5 & 25.5 & 25.5 & 25.5 & 25.5 & 25.5 \\
\hline Humidifier saturation efficiency, $\%$ & 0.95 & 0.95 & 0.95 & 0.95 & 0.95 & 0.95 \\
\hline Carrier gas type & N2 & N2 & N2 & N2 & $\mathrm{N} 2$ & N2 \\
\hline Carrier gas rate, sccm & 500 & 500 & 500 & 500 & 500 & 500 \\
\hline Carrier gas moisture content, vol $\% \mathrm{H} 2$ & 4.8 & 4.8 & 4.8 & 4.8 & 4.8 & 4.8 \\
\hline Total gas flowrate & 525 & 525 & 525 & 525 & 525 & 525 \\
\hline \multicolumn{7}{|l|}{ Other gases } \\
\hline NO ppmv & 10,000 & 10,000 & 10,000 & 10,000 & 10,000 & 10,000 \\
\hline NO2 ppmv & 10,000 & 10,000 & 10,000 & 10,000 & 10,000 & 10,000 \\
\hline NO gas rate, $\mathrm{sccm}$ & 135 & 135 & 135 & 135 & 135 & 135 \\
\hline NO2 gas rate, sccm & 135 & 135 & 135 & 135 & 135 & 135 \\
\hline \multicolumn{7}{|l|}{ Sorption conditions } \\
\hline Temperature, deg. $\mathrm{C}$ & 150 & 150 & 150 & 150 & 150 & 150 \\
\hline Total gas flowrate, sccm & 1,684 & 1,687 & 1,685 & 1,685 & 1,685 & 1,685 \\
\hline T arget $\mathrm{I} 2$ conc, $\mathrm{ppmv}$ & 1.0 & 3.0 & 11 & 11 & 32 & 61 \\
\hline Me asured $I 2$ conc, ppmv & 1.6 & 5.6 & 14.4 & 13.7 & 36.5 & 49.2 \\
\hline Measured total I flowrate, $\mathrm{mg} / \mathrm{min}$ & 0.028 & 0.100 & 0.255 & 0.243 & 0.646 & 0.873 \\
\hline H2O conc, \% & 1.5 & 1.5 & 1.5 & 1.5 & 1.5 & 1.5 \\
\hline $\mathrm{H} 2 \mathrm{O}$ dewpoint, deg. $\mathrm{C}$ & 11 & 11 & 11 & 11 & 11 & 11 \\
\hline NO conc, ppmv & 801 & 800 & 801 & 801 & 801 & 801 \\
\hline $\mathrm{NO} 2$ conc, ppmv & 801 & 800 & 801 & 801 & 801 & 801 \\
\hline Balance & $\mathrm{N} 2$ & $\mathrm{~N} 2$ & $\mathrm{~N} 2$ & $\mathrm{~N} 2$ & $\mathrm{~N} 2$ & $\mathrm{~N} 2$ \\
\hline Sorption gas velocity, $\mathrm{m} / \mathrm{min}$ & 10.0 & 10.0 & 10.0 & 10.0 & 10.0 & 10.0 \\
\hline Bed 1 out residence $t$, sec & 0.076 & 0.076 & 0.076 & 0.076 & 0.076 & 0.076 \\
\hline Bed 2 out cumulative residence $t$, sec & 0.31 & 0.30 & 0.30 & 0.30 & 0.30 & 0.30 \\
\hline Bed 3 out cumulative residence $t$, sec & 0.61 & 0.61 & 0.61 & 0.61 & 0.61 & 0.61 \\
\hline Bed 4 out cumulative residence $t$, sec & 1.22 & 1.22 & 1.22 & 1.22 & 1.22 & 1.22 \\
\hline Cumulative test duration, $\mathrm{hr}$ & 140 & 229 & 36 & 109 & 55 & 48 \\
\hline
\end{tabular}


Table 4-2. AgZ sorption test results.

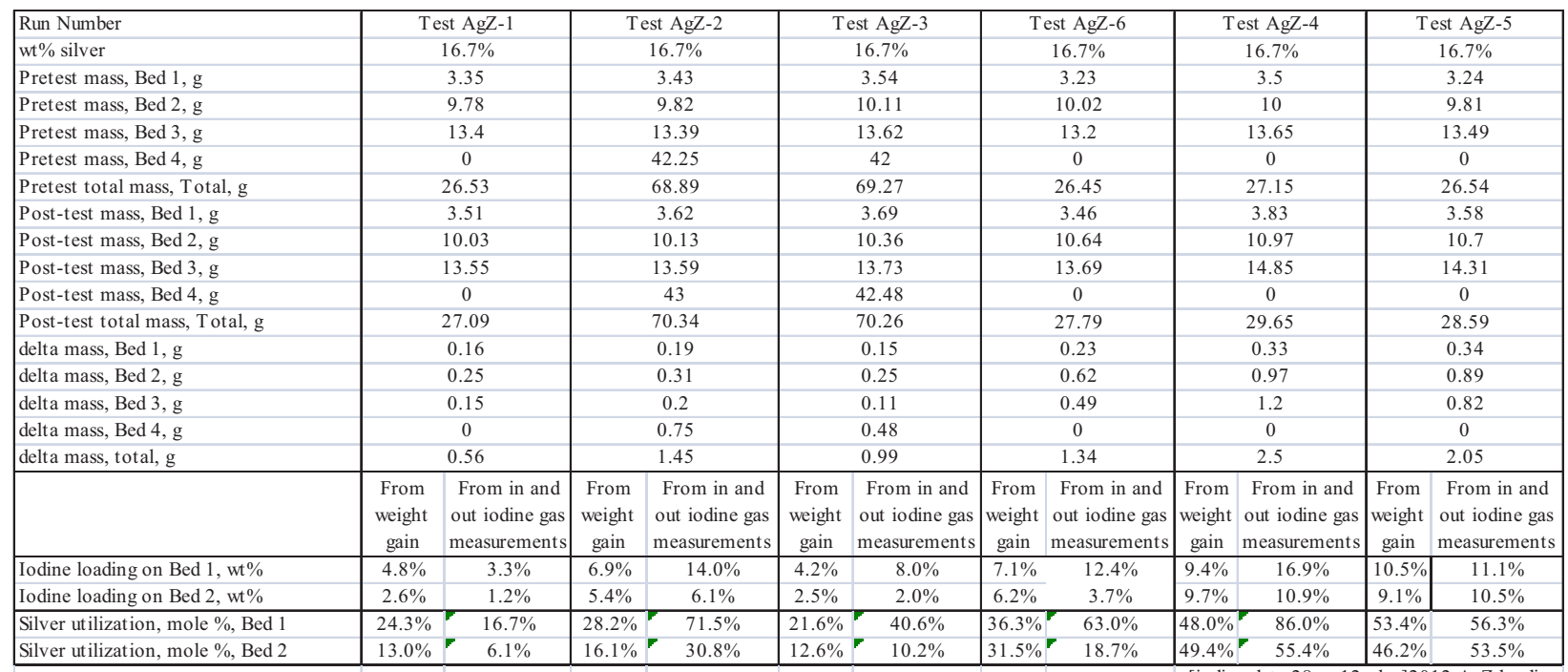

[iodine data 28aug12.xlsx]2012 AgZ loading

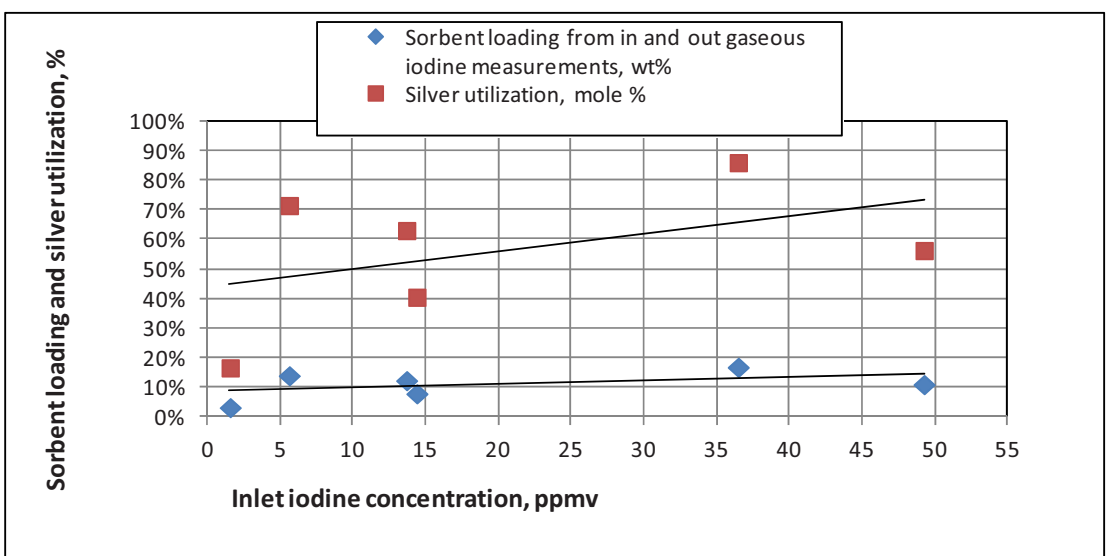

Figure 4-3. Maximum AgZ sorbent loadings based on the inlet and outlet gas iodine concentrations for different inlet gas iodine concentrations.

\subsection{Test AgZ-1 lodine Sorption Results}

Figure 4-4 shows the trends in gaseous iodine concentrations, DFs, and silver utilization on Bed 1 during the 140 hour Test AgZ-1. This figure shows that:

- The initial Bed 1 DF after 0.7 hours of operation was about 30, and it continued to decrease to between 1-2. This indicates that, under the test conditions, the mass transfer zone was at least 0.5 inches deep at the start of the test.

- Since the measured Bed 1 DF never decreased to 1, some iodine capture was still occurring even after test operation for 140 hours. This suggests that as the test proceeds, the depth of the mass transfer zone increased because the sorbent in Bed 1 continued to adsorb iodine. 
- Iodine DFs in Beds 2 and 3 generally ranged between 1,000 to 10,000 for most of the test. The relatively lower DFs and the variations in the DFs for beds 2 and 3 are due in part to values for the bed outlet iodine concentrations that were low and close to the analytical detection limits.

- The Bed 2 DF consistently dropped below 1,000 after about hour 68, indicating that breakthrough had occurred. The long time it took for consistent breakthrough of Bed 2 to occur indicates that the initial depth of the mass transfer zone was less than that the total depth of Beds 1 and 2, a depth of 2 inches, for the first 68 hours of the test. Breakthrough of Bed 3 was not observed during the duration of the test, indicating that the depth of the mass transfer zone did not increase beyond the cumulative depth of Beds 1,2 and 3 (4 inches) during this test.

- Although Bed 1 nearly approached saturation levels of iodine during this test, Beds 2 and 3 did not reach saturation even though breakthrough appears to have occurred in Bed 2.

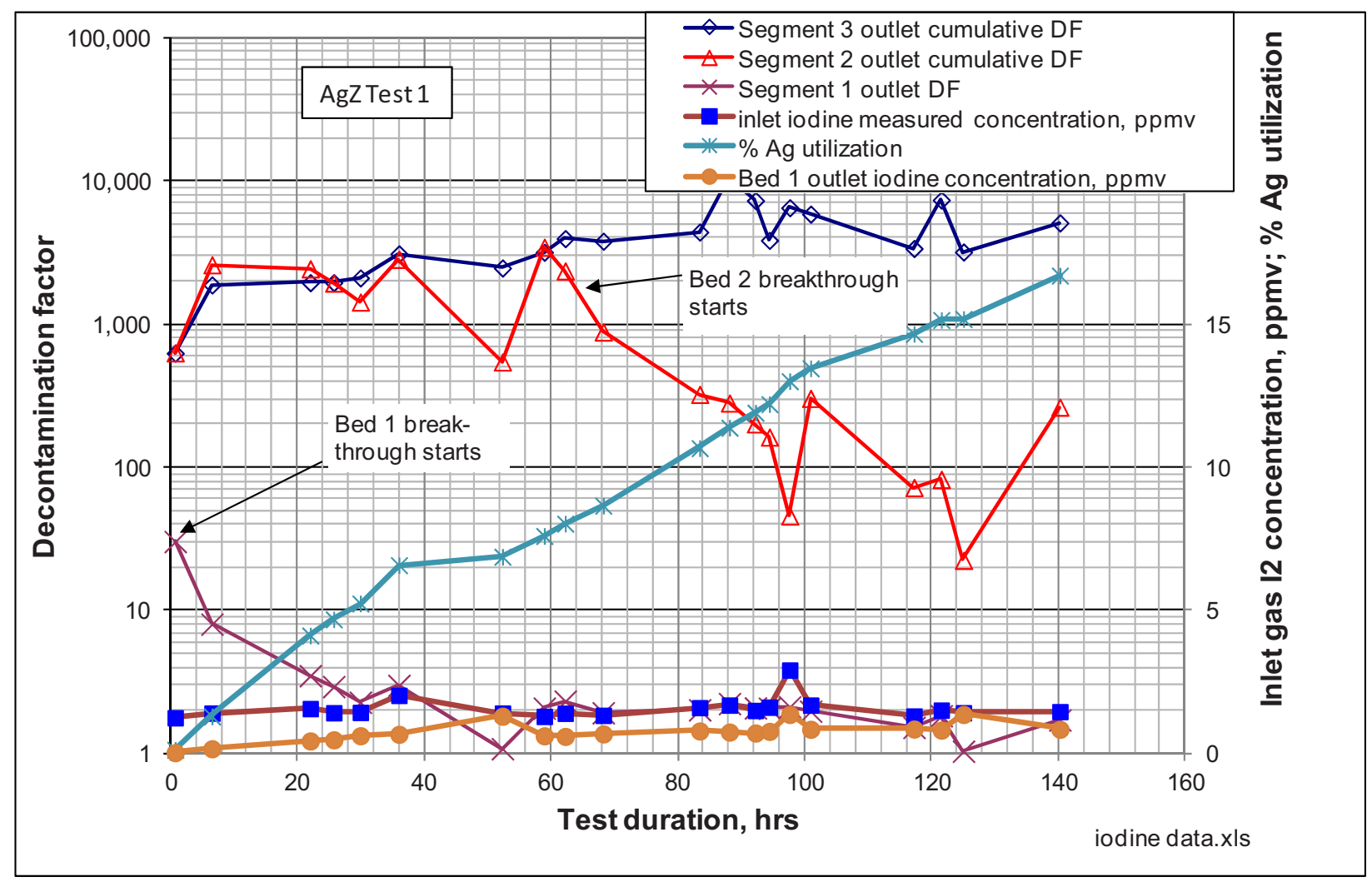

Figure 4-4. Test AgZ-1 iodine sorption results.

After each test, the sorbent beds are purged with pure $\mathrm{N}_{2}$ to desorb any amounts of iodine that may be physisorbed. The purge results for Test AgZ-1 are shown in Figure 4-5. This figure shows that only a small fraction of the iodine adsorbed on Bed 1 was desorbed during the 24-hr purge period. At the start of the purge period, the Bed 1 outlet iodine level was almost one order of magnitude lower than the $\sim 0.9$ ppm range that occurred near the end of the sorption test. This concentration further decreased over another order of magnitude, to essentially the detection limit of the analysis method, after 24 hours of purging. The amount of iodine that was desorbed from Bed 1 started out within the first purge hour at about $0.02 \%$ of the iodine adsorbed on Bed 1 . After 24 purge hours, the cumulative amount of iodine desorbed from Bed 1 increased to about $0.2 \%$ of the adsorbed iodine, and the growth in the cumulative amount was considerably decreasing by that time. 


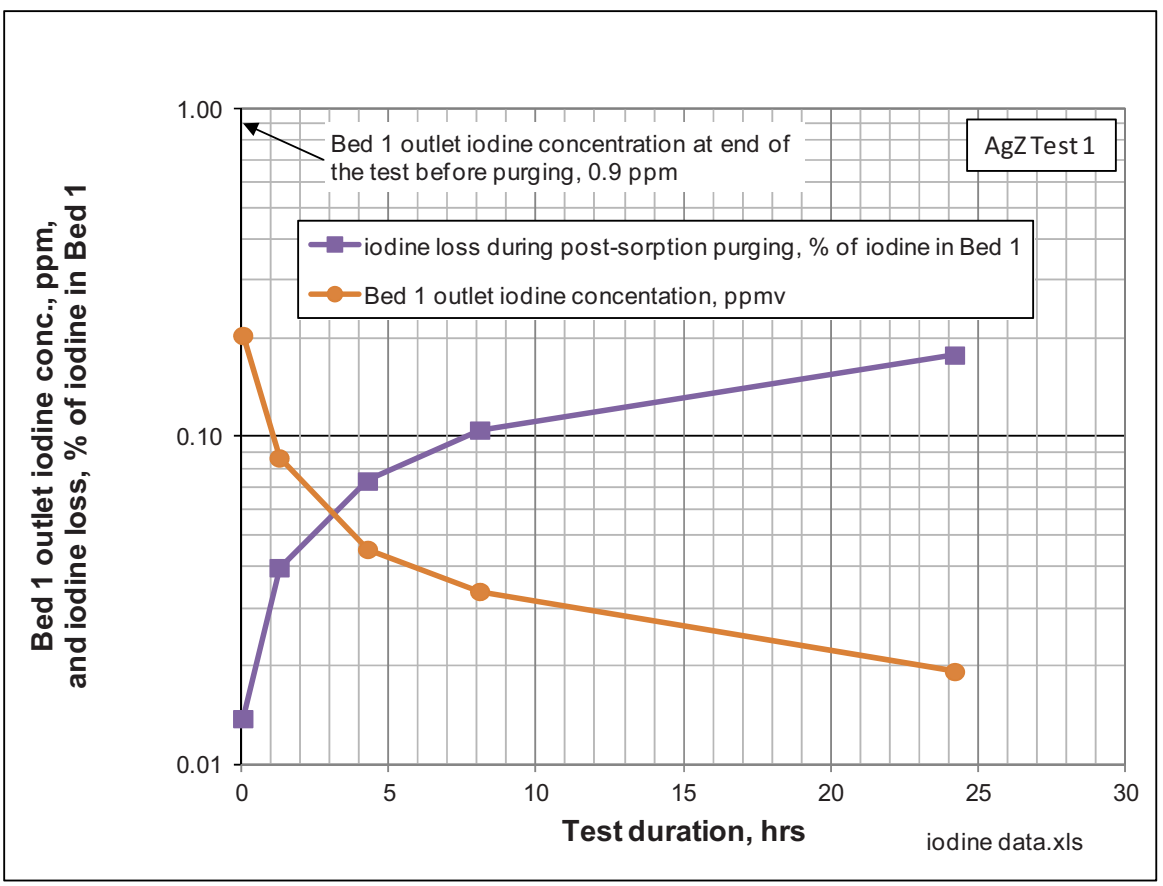

Figure 4-5. Test AgZ-1 purge results.

\subsection{Test AgZ-2 lodine Sorption Results}

Figure 4-6 shows the trends in gaseous iodine concentrations, DFs, and silver utilization on Bed 1 during the 229 hour Test AgZ-2. This figure shows that:

- Iodine quickly broke through Bed 1, and Bed 1 DFs trended between 1-3 for the duration of the test. The mass transfer zone was at least 0.5 inches deep at the start of the test.

- Since the measured Bed 1 DF never decreased to 1, some iodine capture was still occurring even after test operation for 229 hours. This suggests that as the test proceeds, the depth of the mass transfer zone increased because the sorbent in Bed 1 continued to adsorb iodine.

- Iodine DFs in Beds 2 and 3 generally ranged between 10,000 to 50,000 until iodine broke through those beds.

- The Bed 2 DF consistently dropped below 1,000 after about hour 40, indicating that breakthrough had occurred. The time it took for consistent breakthrough of Bed 2 to occur indicates that the initial depth of the mass transfer zone was less than the total depth of Bed 1 and 2 (2 inches) for the first 40 hours of the test. Breakthrough of Bed 3 occurred at about hour 177, indicating that until then, the MTZ depth was less than 4 inches until that time.

- Although Bed 1 approached saturation levels of iodine during this test, Beds 2 and 3 did not reach saturation.

The post-test purge results for Test AgZ-1 are shown in Figure 4-7. Only a small fraction of the iodine adsorbed on Bed $1(0.3 \%)$ was desorbed during the 25 -hr purge period. 


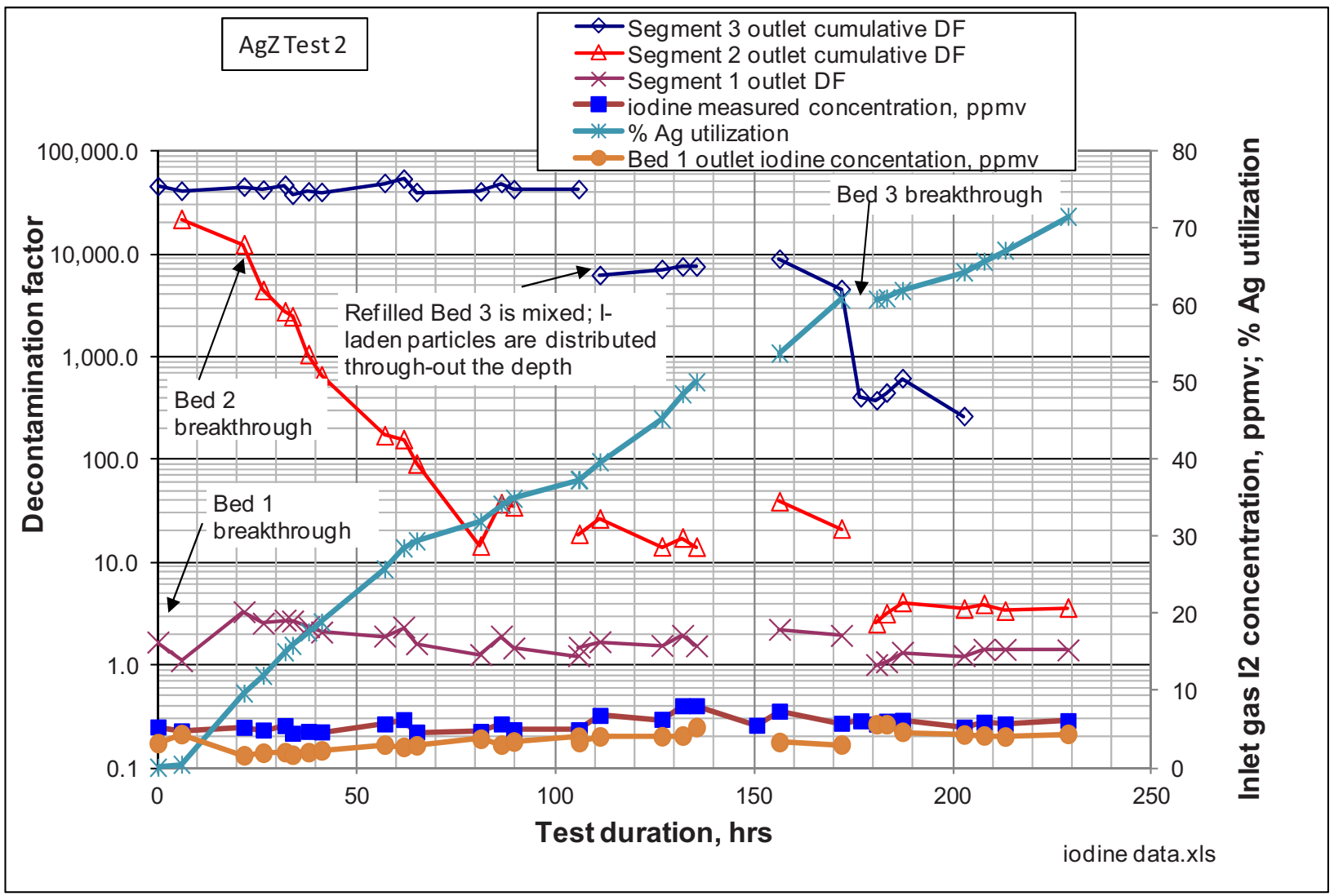

Figure 4-6. Test AgZ-2 iodine sorption results.

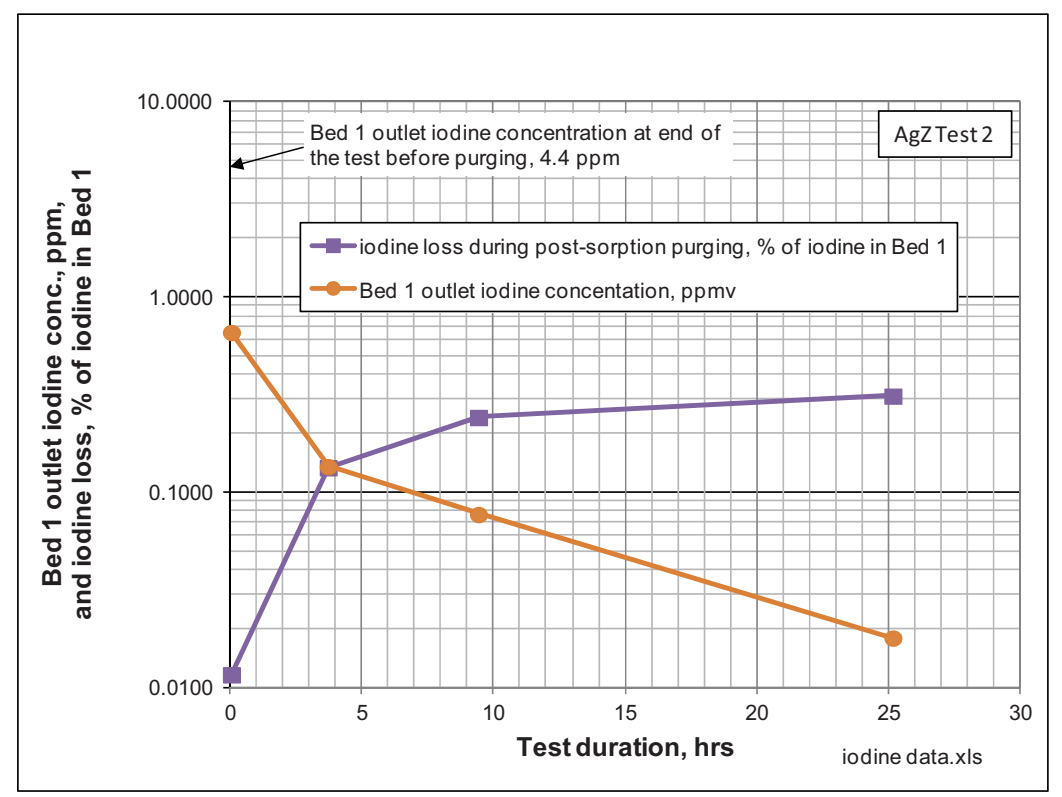

Figure 4-7. Test AgZ-2 purge results. 


\subsection{Test AgZ-3 and AgZ-6 lodine Sorption Results}

Test AgZ-6 was a repeat of AgZ-3, run for a longer duration (109 hours compared to 36 hours), with very close to the same average inlet gas iodine concentration (14.4 pm compared to $13.7 \mathrm{ppm}$ ) when it was determined that some test durations needed to be longer to more closely approach iodine saturation levels in at least Bed 1. Figures 4-8 and 4-9 show the trends in gaseous iodine concentrations, DFs, and silver utilization on Bed 1 during these tests. These figures show that:

- Test AgZ-3 appears to be similar to the first $~ 30$ hours of Test AgZ-6, as to be expected. While iodine broke through Beds 1 and 2 in both tests at about the same time (in less than 1 hour for Bed 1 and after about 10-16 hours for Bed 2), Bed 3 broke through only in the longer-duration Test AgZ-6. The mass transfer zone was at least 0.5 inches deep at the start of these tests.

- Since the measured Bed 1 DF never decreased consistently to 1, some iodine capture was still occurring even after test operation for 109 hours in Test AgZ-6. This suggests that as the test proceeds, the depth of the mass transfer zone increased.

- Iodine DFs in Beds 2 and 3 generally ranged as high as 100,000 until iodine broke through those beds. The MTZ depth gradually increased from under 2 inches to over 4 inches during the Test AgZ-6.

The post-test purge results for tests AgZ-3 and AgZ-6 are shown in Figures 4-10 and 4-11. With less adsorbed iodine after AgZ-3, the fraction of the iodine that desorbed, at about $0.06 \%$ of the adsorbed iodine, was less than for AgZ-6, which had about $0.6 \%$ desorbed iodine. 


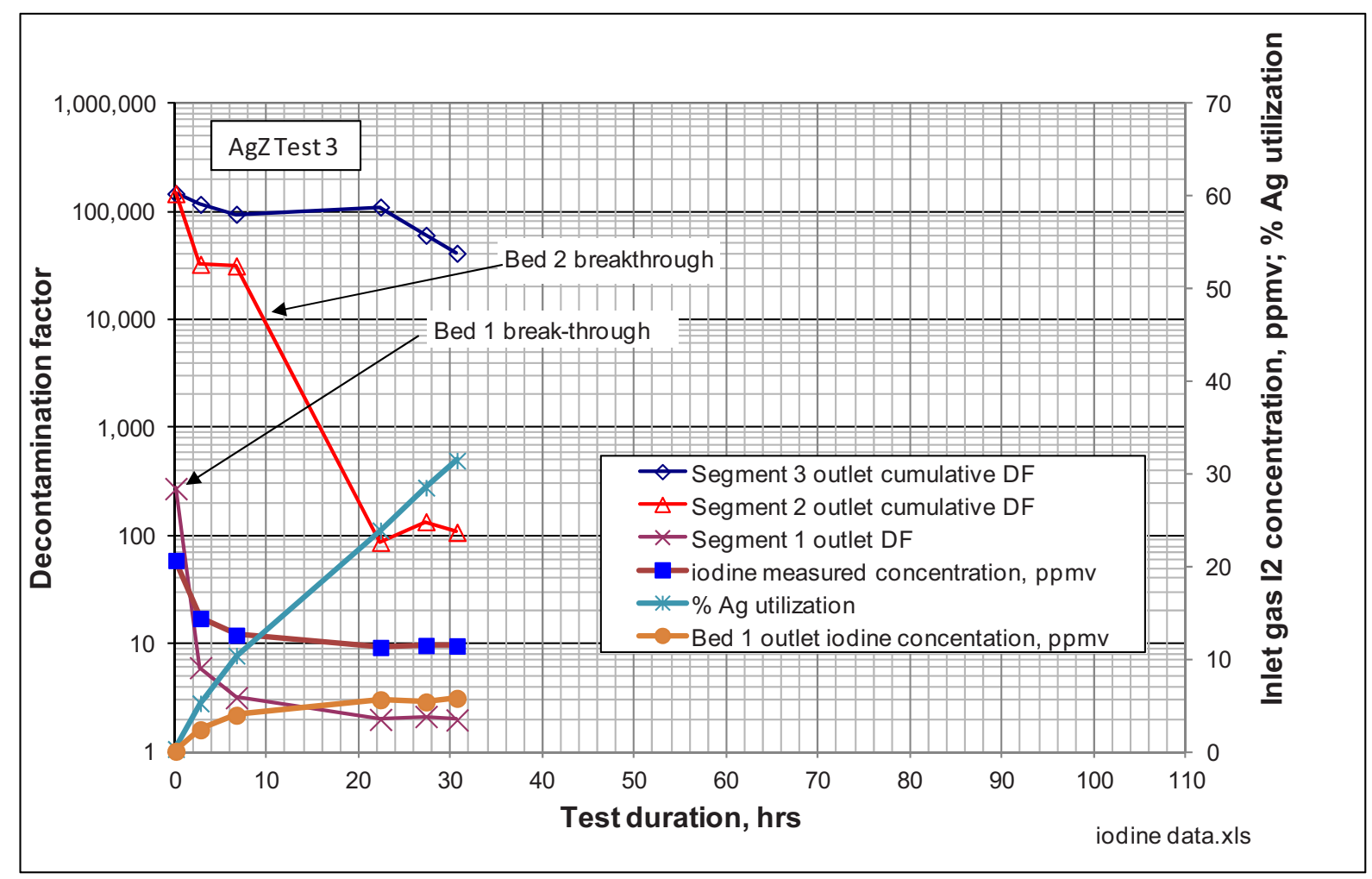

Figure 4-8. Test AgZ-3 iodine sorption results.

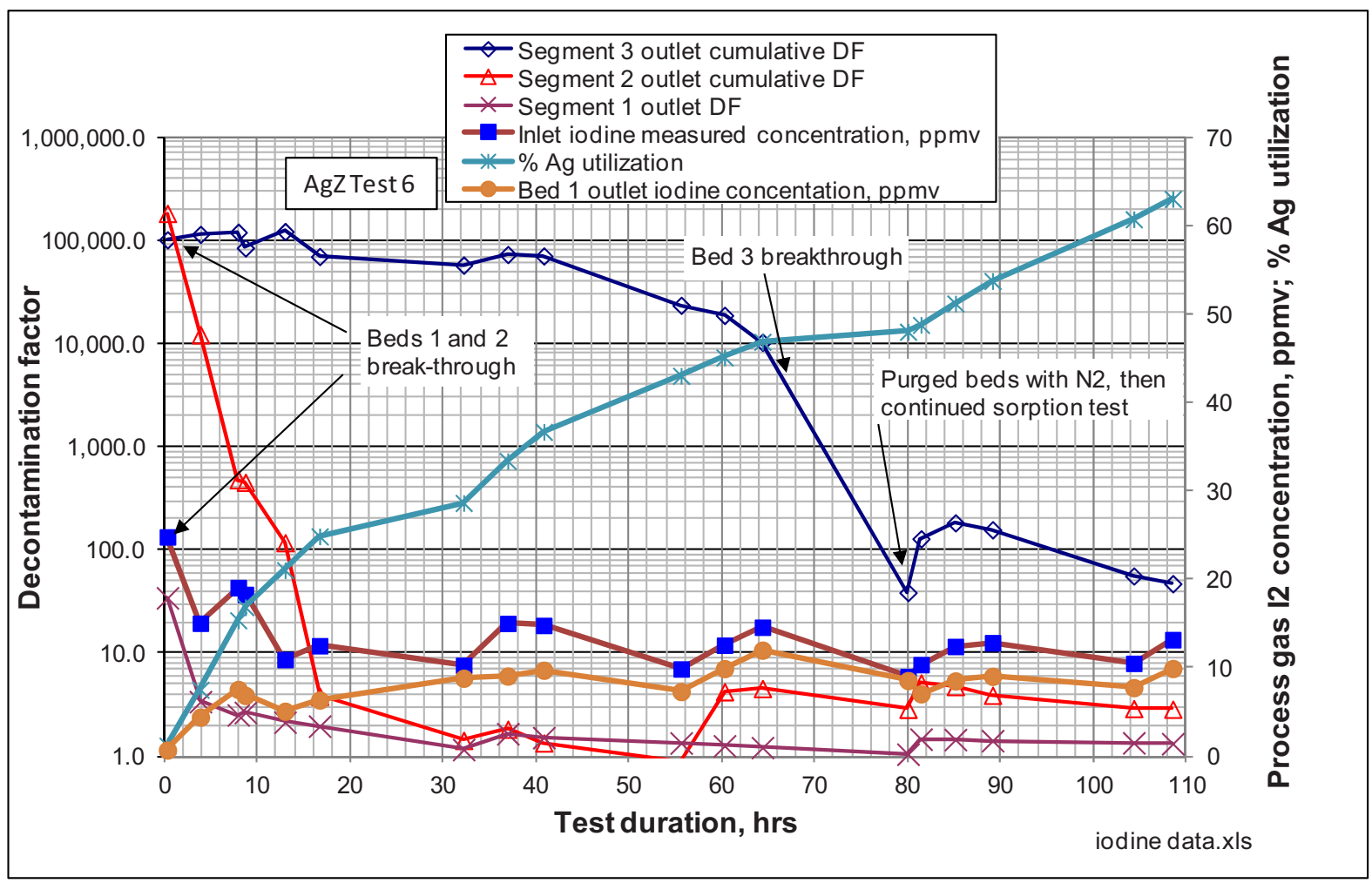

Figure 4-9. Test AgZ-6 iodine sorption results. 


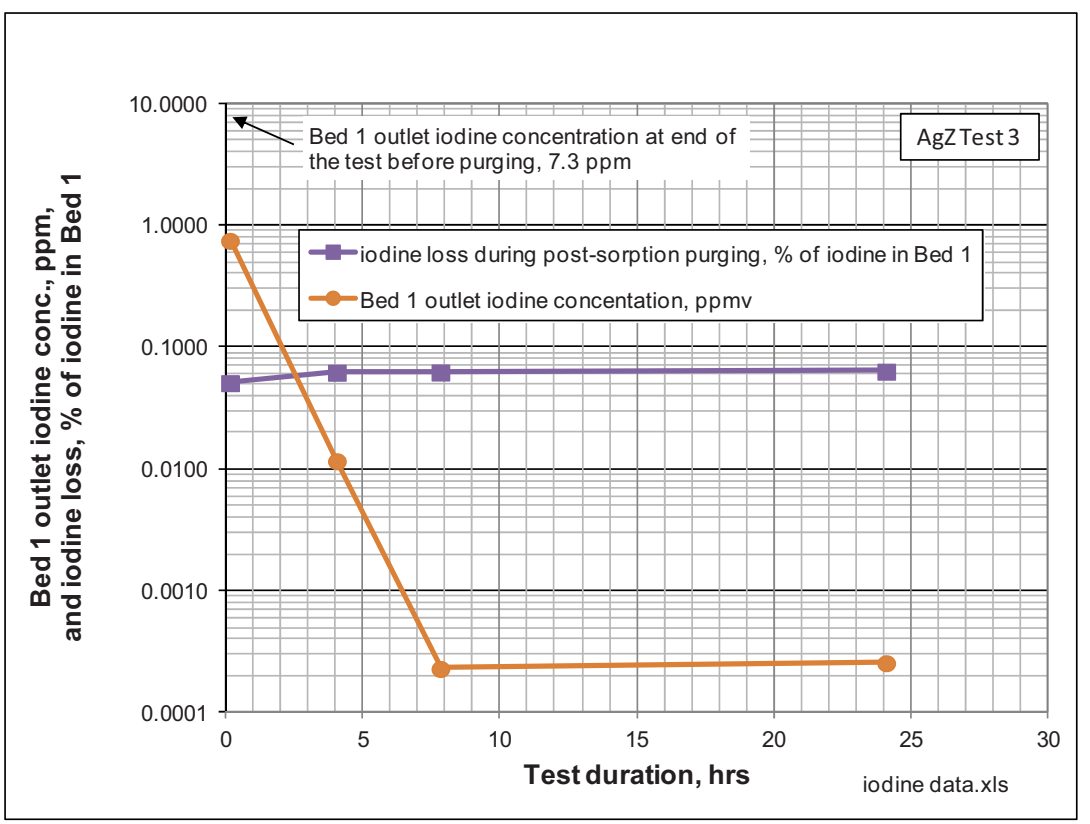

Figure 4-10. Test AgZ-3 purge results.

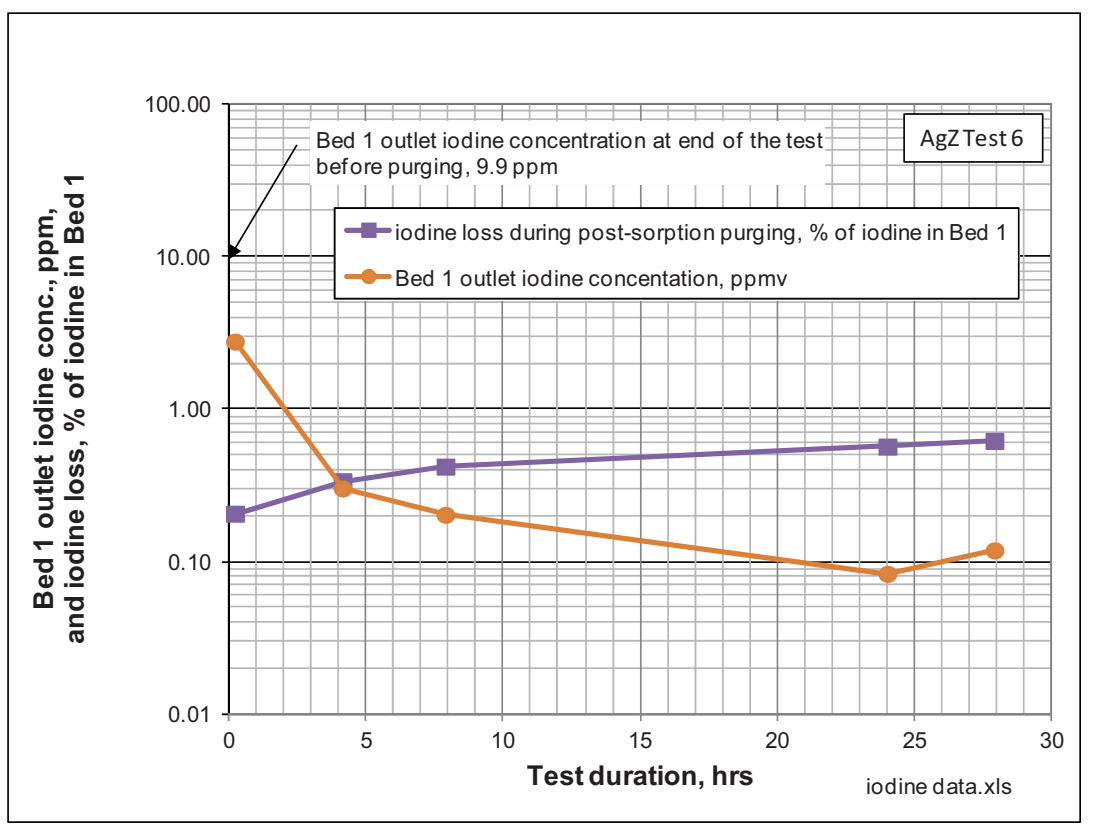

Figure 4-11. Test AgZ-6 purge results.

\subsection{Test AgZ-5 lodine Sorption Results}

Figure 4-12 shows the trends in gaseous iodine concentrations, DFs, and silver utilization on Bed 1 during the 55 hour Test AgZ-5. This figure shows that: 
- Iodine quickly broke through Bed 1, and Bed 1 DFs trended between 1-2 for the duration of the test after about hour 8 . Bed 1 closely approached saturation, but the silver utilization (determined from the gas-phase iodine measurements) was calculated at about $56 \%$, indicating that Bed 1 may continue to adsorb iodine at a low efficiency for some additional time before reaching saturation.

- Iodine DFs in Beds 2 and 3 were initially high, ranging between 10,000 to 30,000 until the iodine broke through those beds, which occurred fairly quickly (under 5 hours for Bed 2 and under about 34 hours for Bed 3).

- The initial MTZ was under 2 inches, but by hour 34 the MTZ had increased to at least 4 inches.

- Although beds 1 and 2 approached saturation levels of iodine during this test (with DFs between 1-3), Bed 3, with a DF of about 10 at the end of the test, did not reach saturation.

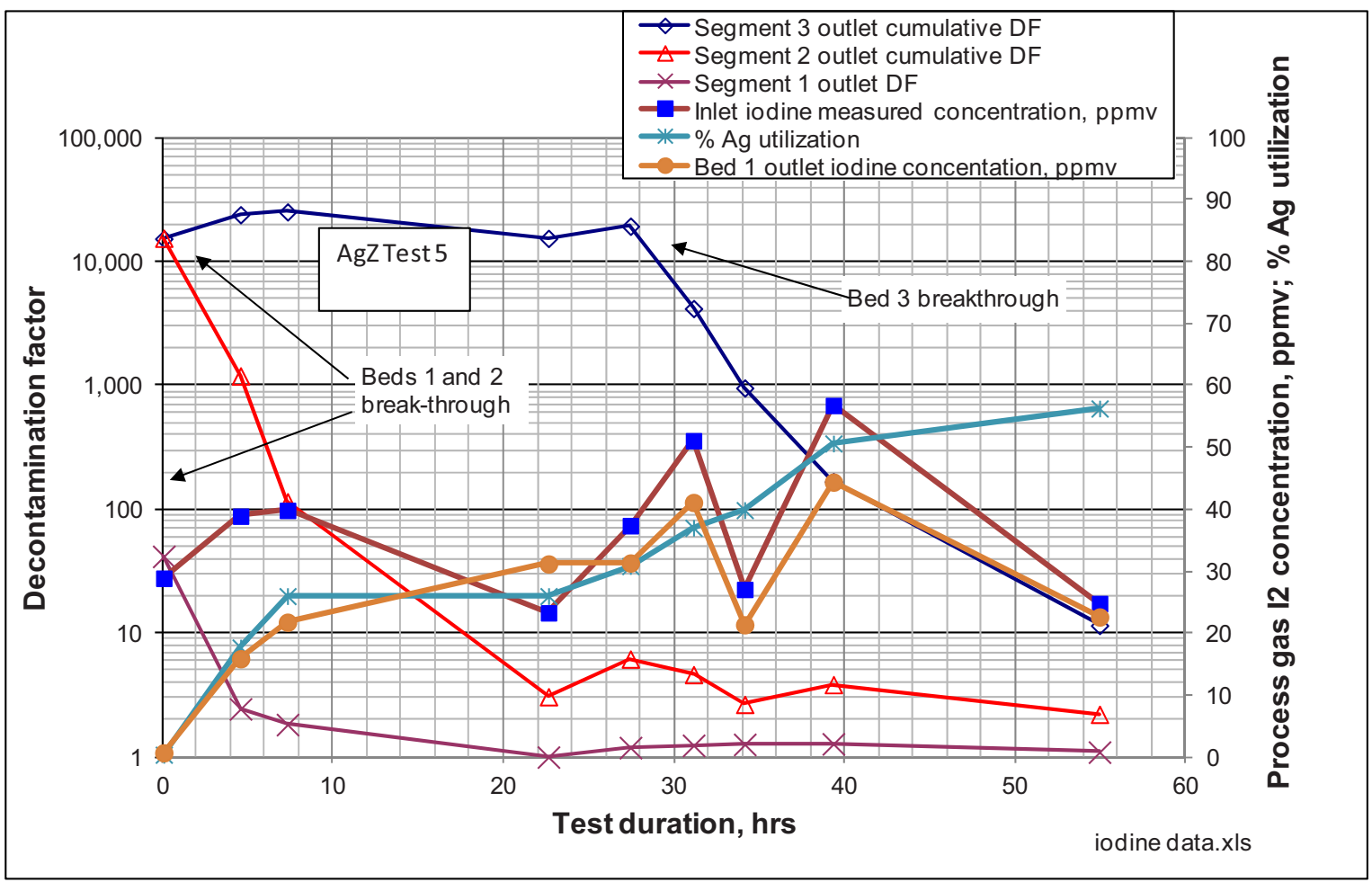

Figure 4-12. Test AgZ-5 iodine sorption results.

The post-test purge results for Test AgZ-5 are shown in Figure 4-13. Only a small fraction of the iodine adsorbed on Bed $1(0.6 \%)$ was desorbed during the 28 -hr purge period. 


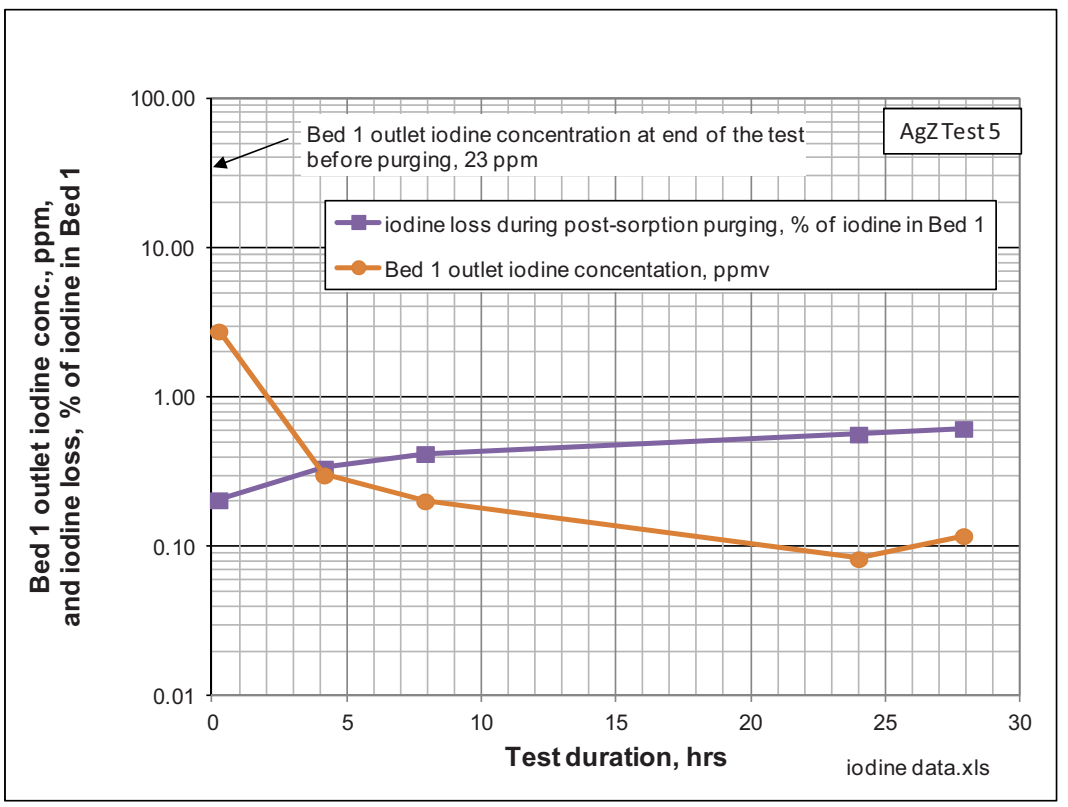

Figure 4-13. Test AgZ-5 purge results.

\subsection{Test AgZ-4 lodine Sorption Results}

Figure 4-14 shows the trends in gaseous iodine concentrations, DFs, and silver utilization on Bed 1 during the 48 hour Test AgZ-4. Test AgZ-4 had the highest average inlet gas iodine concentration (at 49 ppmv) of all the $\mathrm{AgZ}$ tests performed this year. This figure shows that:

- Iodine quickly broke through Bed 1, and Bed 1 DFs trended between 1-2 for the duration of the test after about hour 10. Bed 1 closely approached saturation, with a silver utilization (determined from the gas-phase iodine measurements) of about $86 \%$.

- Iodine DFs in Beds 2 and 3 were initially high, ranging between 50,000 to 90,000 until the iodine broke through those beds, which occurred fairly quickly (under 3 hours for Bed 2 and under about 20 hours for Bed 3).

- The initial MTZ was under 2 inches, but by hour 20 the MTZ had increased to at least 4 inches.

- Although beds 1 and 2 approached saturation levels of iodine during this test (with DFs between $1-2$ ), Bed 3, with a DF of about 4 at the end of the test, did not reach saturation.

The post-test purge results for Test AgZ-4 are shown in Figure 4-15. Only a small fraction of the iodine adsorbed on Bed $1(0.6 \%)$ was desorbed during the 3.5-hr purge period. 


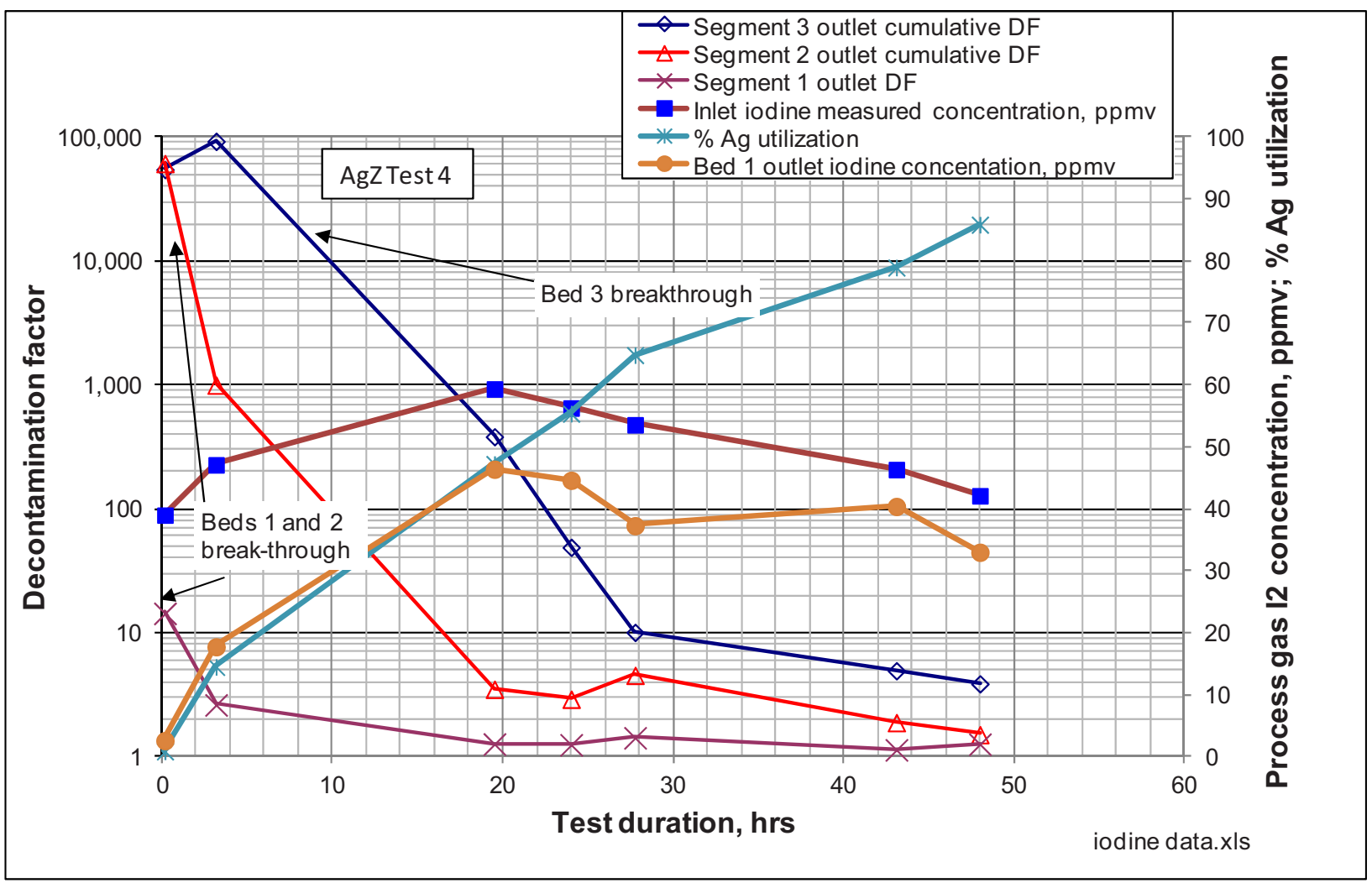

Figure 4-14. Test AgZ-4 iodine sorption results.

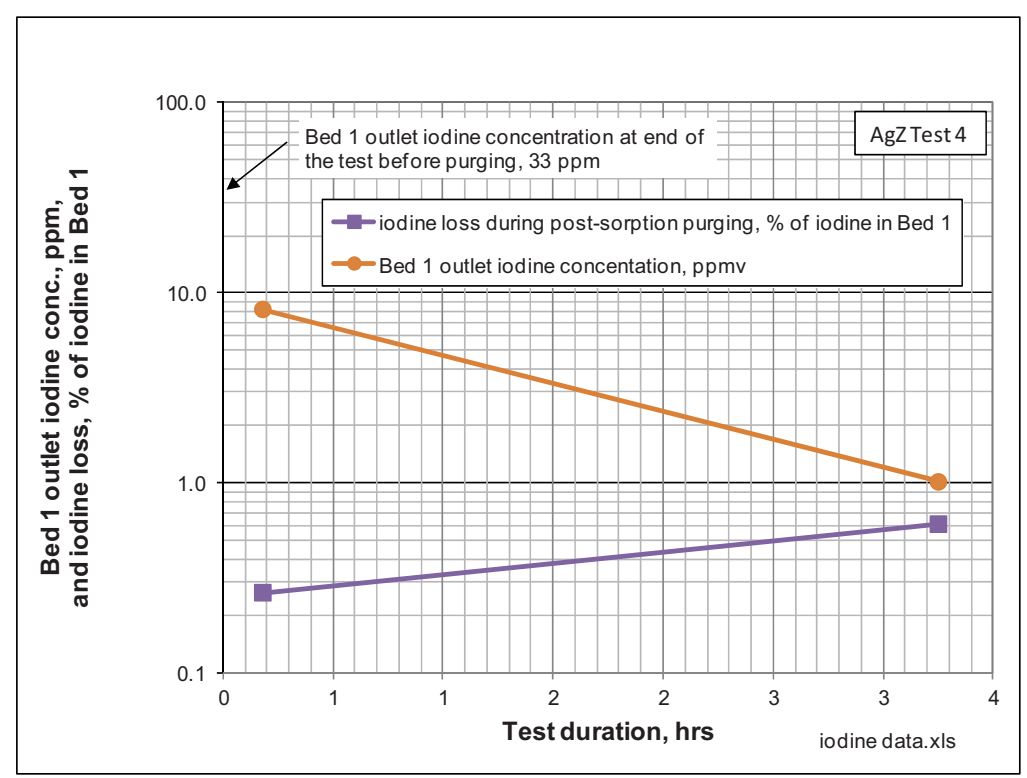

Figure 4-15. Test AgZ-4 purge results. 


\section{CONCLUSIONS AND RECOMMENDATIONS}

Tests of both silver-functionalized Aerogel and silver zeolite sorbents showed that:

- Decontamination factors were achieved that exceed reasonably conservative estimates for DFs needed for used fuel reprocessing facilities in the U.S. to meet regulatory requirements for I-129 capture.

- Silver utilizations approached or exceeded $100 \%$ for high inlet gas iodine concentrations, but test durations were not long enough to approach $100 \%$ silver utilization for lower iodine concentrations.

- The depth of the mass transfer zone was determined for both low iodine concentrations (under 10 ppmv) and for higher iodine concentrations (between 10-50 ppmv). Higher inlet iodine concentrations cause deeper MTZs because of the increased mass transfer that has to occur; also, the MTZ depth increases over time as the iodine is adsorbed.

- The portion of adsorbed iodine that tends to desorb because it is not chemisorbed (reacted to form $\mathrm{AgI}$ ) is small, under $1 \%$, for the $\mathrm{AgZ}$ tests, and even smaller, under $0.01 \%$, for the silverfunctionalized Aerogel.

\subsection{Silver-functionalized Aerogel}

The silver-functionalized Aerogel appears to have potential to be a very effective and efficient iodine sorbent. Under the test conditions, the iodine DFs ranged between 10,000 to 100,000 before breakthrough. These high DFs exceed reasonably conservative estimates for DFs needed for used fuel reprocessing facilities in the U.S. to meet regulatory requirements for I-129 capture.

Sorbent loadings for iodine ranged from 20-46 wt\% (g iodine per $100 \mathrm{~g}$ sorbent) determined by gaseous inlet and outlet iodine measurements, and $11-20 \mathrm{wt} \%$ determined gravimetrically. The highest inlet iodine concentrations resulted in the highest loadings, although in all of the tests, the gas-phase iodine measurements indicated that sorption was still occurring even in the first bed. Therefore, the maximum capacity of the sorbent at the test conditions may be higher than the measured loadings. Additional spent sorbent analyses need to be done to better evaluate this difference in measured iodine loadings in the two measurement methods. These loadings reflect silver utilizations of $58-130 \%$ based on the gaseous iodine measurements, and $32-57 \%$ based on weight gain.

The depth of the mass transfer zone varied for different inlet iodine concentrations and test durations:

- When the average inlet iodine concentration was 2 ppmv, the MTZ depth was 0.5-2 inches for up to 200 hours, and 2-4 inches for up to 240 hours.

- When the inlet iodine concentration was 8 ppmv, the MTZ depth was 0.5-2 inches for up to 20 hours; 2-4 inches for up to about 40 hours; and over 4 inches after 40 hours.

- When the inlet iodine concentration was 34 ppmv, the MTZ depth was 2-4 inches for up to about 40 hours; and over 4 inches after 40 hours.

The silver-functionalized Aerogel captures iodine by chemisorption, where the adsorbed iodine reacts with the silver to form very non-volatile AgI. Any iodine that is physisorbed but not chemically reacted with silver to form AgI might not be tightly held by the sorbent. Very small amounts, ranging from $0.003-0.004 \%$ of the adsorbed iodine, were desorbed during desorption periods of up to 31 hours, even for the test in which the calculated silver utilization (based on gaseous iodine measurements) was 130\%. 


\subsection{Silver Zeolite}

The AgZ also performed well in these tests. Under the test conditions, the iodine DFs ranged between 10,000 to 100,000 before breakthrough, essentially equal to those measured for the silverfunctionalized Aerogel.

Sorbent loadings for iodine ranged from 3.3-17 wt $\%$ (g iodine per $100 \mathrm{~g}$ sorbent) determined by gaseous inlet and outlet iodine measurements, and 4.2-11 wt $\%$ determined gravimetrically. The highest inlet iodine concentrations resulted in the highest loadings, although in all of the tests, the gas-phase iodine measurements indicated that sorption was still occurring even in the first bed. Therefore, the maximum capacity of the sorbent at the test conditions may be higher than the measured loadings. Additional spent sorbent analyses need to be done to better evaluate this difference in measured iodine loadings in the two measurement methods. These loadings reflect silver utilizations of $17-86 \%$ based on the gaseous iodine measurements, and $22-53 \%$ based on weight gain.

The depth of the mass transfer zone varied for different inlet iodine concentrations and test durations:

- When the average inlet iodine concentration was 1.6-5.6 ppmv, the MTZ depth was 0.5-2 inches for up to 70 hours, and 2-4 inches for up to 170 hours.

- When the inlet iodine concentration was 13.7-14.4 ppmv, the MTZ depth was 0.5-2 inches for up to 10 hours; 2-4 inches for up to about 70 hours; and over 4 inches after 70 hours.

- When the inlet iodine concentration was 37-49 ppmv, the MTZ depth was 2-4 inches for up to about 34 hours; and over 4 inches after 34 hours.

The AgZ captures iodine by chemisorption, where the adsorbed iodine reacts with the silver to form very non-volatile AgI. Any adsorbed iodine that is physisorbed but not chemically reacted with silver to form AgI might not be tightly held by the sorbent. Small amounts, ranging from $0.2-0.6 \%$ of the adsorbed iodine, were desorbed during desorption periods of up to 28 hours. This amount of desorption is about 2 orders of magnitude higher than the desorption rate for the silver-functionalized Aerogel.

\section{REFERENCES}

INL 2011

Jubin 2011

Jubin 2012

Pantano 2011

Soelberg 2008

Soelberg 2011

Soelberg 2012
“Gas Phase Iodine Capture Methods for Non-Radioactive Materials," Laboratory Instruction 1287-070CFA, Revision 3, eCR No. 583874, February 16, 2011.

Jubin, Bob, et al, "Assessments and Options for Removal and Immobilization of Volatile Radionuclides from the Processing of Used Nuclear Fuel," FCR\&D-SWR2011-000305, 31 August 2011.

Jubin, R.T, N.R. Soelberg, D.M. Strachan, and G. Ilas, "Position Paper on Practicable Performance Criteria for the Removal Efficiency of Volatile Radionuclides," FCRDSWF-2012-000091, INL-EXT-12-25410, March 30, 2012.

Pantano, Carlo, Tom Thomas, Jack Watson, and Chris Phillips, "FCR\&D Off-Gas Sigma Team Peer Review, June 23-24, 2011.

Soelberg, Nick, Mike Abbott, Daryl Haefner, and Bob Jubin, "Gaseous Fission Product Emissions Control During Spent Nuclear Fuel Recycling," $235^{\text {th }}$ ACS National Meeting and Exposition, New Orleans, LA, April 6-10, 2008.

Soelberg, Nick and Veronica Rutledge, "Test Plan for Deep-Bed Iodine Sorption Studies: FY 12," unpublished Idaho National Laboratory document, December 2011.

Soelberg, Nick and Tony Watson, "Deep Bed Adsorption Testing using SilverFunctionalized Aerogel,” FCRD-SWF-2012-000173, INL/EXT-12-26522, June 29, 2012. 